\title{
Utilizing a Rapid Multi-Plug Filtration Cleanup Method for 72 Pesticide Residues in Grape Wines Followed by Detection with Gas Chromatography Tandem Mass Spectrometry
}

\author{
Shaowen Liu ${ }^{1,2}$, Aijuan Bai ${ }^{1}$, Le Song ${ }^{1}$, Nan Zou ${ }^{1}$, Yongtao Han ${ }^{1}$, Li Zhou ${ }^{3}$, Chuanshan Yu ${ }^{1}$, Changjun Li ${ }^{2}$ \\ and Canping Pan ${ }^{1, *}$ \\ 1 Department of Applied Chemistry, College of Science, China Agricultural University, Beijing 100193, China; \\ Shaowenliu2016@163.com (S.L.); baiaijuan678@163.com (A.B.); songle0626@163.com (L.S.); \\ zounan5211314@163.com (N.Z.); ythan@rcees.ac.cn (Y.H.); chuanshan.yu@gmail.com (C.Y.) \\ 2 Hunan Institute of Agricultural Environment and Ecology, Changsha 410125, China; ricroot@sina.com \\ 3 Tea Research Institute, Chinese Academy of Agricultural Sciences, Hangzhou 310008, China; \\ lizhou@tricaas.com \\ * Correspondence: canpingp@cau.edu.cn; Fax: +86-10-6273-3620
}

\section{check for}

updates

Citation: Liu, S.; Bai, A.; Song, L.; Zou, N.; Han, Y.; Zhou, L.; Yu, C.; Li, C.; Pan, C. Utilizing a Rapid Multi-Plug Filtration Cleanup Method for 72 Pesticide Residues in Grape Wines Followed by Detection with Gas Chromatography Tandem Mass Spectrometry. Foods 2021, 10, 2731. https://doi.org/10.3390/ foods10112731

Academic Editor: Evaristo Ballesteros

Received: 21 August 2021

Accepted: 2 November 2021

Published: 8 November 2021

Publisher's Note: MDPI stays neutral with regard to jurisdictional claims in published maps and institutional affiliations.

Copyright: (c) 2021 by the authors. Licensee MDPI, Basel, Switzerland. This article is an open access article distributed under the terms and conditions of the Creative Commons Attribution (CC BY) license (https:// creativecommons.org/licenses/by/ $4.0 /)$.
Abstract: A convenient and fast multi-residue method for the efficient identification and quantification of 72 pesticides belonging to different chemical classes in red and white grape wines has been developed. The analysis was based on gas chromatography tandem quadrupole mass spectrometric determination (GC-MS/MS). The optimization strategy involved the selection of the amount of multi-walled carbon nanotubes (MWCNTs) and the number of cleanup procedure cycles for multiplug filtration cleanup (m-PFC) to achieve ideal recoveries and reduce the sample matrix compounds in the final extracts. The optimized procedure obtained consistent recoveries between 70.2 and $108.8 \%$ (70.2 and $108.8 \%$ for white wine, and 72.3 and $108.4 \%$ for red wine), with relative standard deviations (RSDs) that were generally lower than $9.2 \%$ at the three spiking levels of $0.01,0.05$ and $0.1 \mathrm{mg} / \mathrm{kg}$. The linearity was studied in the range between 0.002 and $0.1 \mathrm{mg} / \mathrm{kg}$ using pesticide standards prepared both in pure solvent and in the presence of the matrix, showing coefficients of determination $\left(R^{2}\right)$ higher than 0.9495 for all the pesticides. To improve accuracy, matrix-matched calibration curves were used for calculating the quantification results. Finally, the method was used successfully for detecting pesticide residues in commercial grape wines.

Keywords: pesticide residue; GC-MS/MS; m-PFC; wine

\section{Introduction}

Grape wine is one of the most commonly consumed alcoholic beverages in the world. In addition to its distinctive flavor, the moderate consumption of wine is correlated with reduced risks of both mortality and morbidity from human cardiovascular disease [1] and oxidative damage [2]. The worldwide consumption of wine is increasing steadily and has reached up to $240 \mathrm{Mhl}$ per year, according to records collected by the International Organisation of Vine and Wine over recent years [3].

During the grape cultivation period, it is common practice in vineyards to use pesticides, such as fungicides, insecticides and herbicides, to obtain high production. Grapes receive multiple doses of pesticides, which may partly transfer into wine [4-8]. In previous market surveillance studies [9-13], metalaxyl, procymidone, fenhexamid, cyprodinil, azoxystrobin and iprodione were detected in commercial grape wines; tebuconazol, metalaxyl and cyprodinil represent the most frequently detected pesticides. The risk of residues from these pesticides being present in wines implies a health hazard. For this reason, there are maximum residue limits (MRLs) set by current legislation [14]. To date, and with regard to grapevine products, MRLs have only been set for grapes, taking the transfer in the wine into account. The MRLs for wine are still not widely established [15-17]. Therefore, it 
is important to develop simple, rapid, environmentally friendly and sensitive analytical methods for the determination of trace levels of pesticide residues in wine samples in order to evaluate their safety and possible risk to human health.

Sample preparation is considered one of the most important steps in any procedure of pesticide residue analysis. The analysis of pesticide residues in wine is challenging due to the complexity of the matrix, which contains alcohol, organic acids, sugars and polyphenols (e.g., anthocyanins, flavonols and tannins). Many effective preparation methods of wine samples have been reported, including liquid-liquid extraction (LLE) with different organic solvents [11,18-20], solid-phase extraction (SPE) with reversed-phase C18 or polymeric sorbents [21-27], solid-phase microextraction (SPME) [22,28,29] and ultrasound-assisted emulsification microextraction (USAEME) [28,30], single drop liquid-liquid microextraction (LLME) [31-34], membrane-assisted solvent extraction [4] and dispersive liquid-liquid microextraction (DLLME) [35-37].

The QuEChERS (Quick, Easy, Cheap, Effective, Rugged and Safe) method is a sample preparation technique that was first reported in 2003 by Anastassiades et al. [38]. The QuEChERS cleanup technique belongs to the dispersive solid-phase extraction (dispersive SPE) class [39]. To date, there have been many reports on the application of QuEChERSbased methods for analyzing pesticides in wines [7,17,40-49].

Carbon nanotubes (CNTs) are novel and interesting carbonaceous materials first reported by Iijiama in 1991 [50]. These are classified into single-walled carbon nanotubes (SWCNTs) and multi-walled carbon nanotubes (MWCNTs) on the basis of the carbon atom layers in the walls of the nanotubes [51,52]. In recent years, MWCNTs have been reported to be used as effective SPE materials in the extraction of pesticides [53-56].

In our previous study, MWCNTs were used as alternative reversed-dispersive solid phase extraction materials in the multi-residue analysis of pesticides via the QuEChERS method [57-59]. They were mixed with other sorbents such as PSA, GCB and C18 for the dispersive cleanup of acetonitrile extracts from complex samples such as tea [58], scallions, ginger and garlic [60,61]. The new multi-plug filtration cleanup (m-PFC, Figure 1) procedure developed by our group, the solid-phase sorbents which were constituted with MWCNTs, other sorbents and anhydrous magnesium sulfate were packed in a short syringe cartridge. The syringe needle was kept under the surface of the extract, and the syringe piston was pushed and pulled for several cycles in order to adsorb the interfering substances and to remove water. The m-PFC method was very rapid, taking about $10 \mathrm{~s}$ to perform without any solvent evaporation [59,62-64].
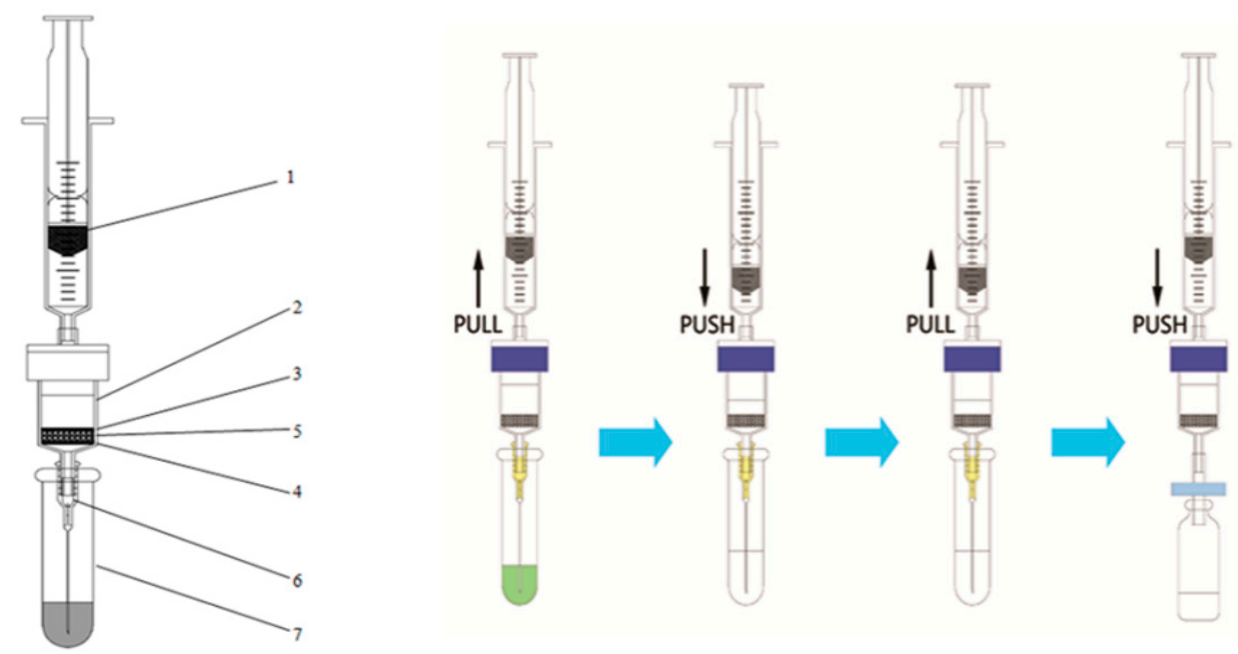

Figure 1. Schematic diagram of an $\mathrm{m}-\mathrm{PFC}$ setup (original drawing from Zhao et al. [62]): 1, syringe; 2, column; 3, PE filter (upper); 4, PE filter (lower); 5, MWCMNs (10 mg) and anhydrous magnesium sulfate $(150 \mathrm{mg}) ; 6$, syringe needle; 7, $2.0 \mathrm{~mL}$ microcentrifuge tube. 
The main objective of this work was to develop a fast, sensitive and reliable analytical $\mathrm{m}$-PFC method. In this work, 72 pesticides with different chemical structures in wine were determined using GC-MS/MS. This method was successfully applied for market survey samples.

\section{Materials and Methods}

\subsection{Chemicals and Materials}

The initial sample preparation was identical to that used for the QuEChERS method [38]. Standard compounds were provided by the Institute of the Control of Agrochemicals, Ministry of Agriculture, China. The purity of the standard pesticides was 95-99\%. Stock solutions of $10 \mathrm{mg} / \mathrm{L}$ of the pesticide mixture were prepared in acetonitrile and stored at $-20^{\circ} \mathrm{C}$. The working solutions were prepared daily. HPLC-grade acetonitrile was obtained from Fisher Chemicals (Fair Lawn, NJ, USA). Analytical-reagent-grade anhydrous sodium chloride $(\mathrm{NaCl})$ and magnesium sulfate $(\mathrm{MgSO} 4)$ were obtained from Sinopharm Chemical Reagent (Beijing, China). Tianjin Bonna-Agela Technologies (Tianjin, China) provided MWCNTs with different average external diameters and PSA. The MWCNTs were dried for $2 \mathrm{~h}$ at $120{ }^{\circ} \mathrm{C}$ to remove the absorbed water and then kept in desiccators for storage.

\subsection{Apparatus and Conditions}

Centrifugation was performed with two different instruments: an Anke TDL-40B centrifuge equipped with a bucket rotor $(4 \times 100 \mathrm{~mL})$ (Shanghai, China) and a SIGMA 3K15 microcentrifuge equipped with angular rotor $(24 \times 2.0 \mathrm{~mL})$ (Sigma Laborzentrifugen $\mathrm{GmbH}$, Osterode am Harz, Germany). A QL-901 Vortex (Kylin-bell Lab Instruments, Jiangsu, China) was used for preparing the samples. A Meiling BCD-245W refrigerator freezer (Beijing, China) was used to control the temperature of the samples.

Determinations were performed using an Agilent 7000 A triple-quadrupole mass spectrometer interfaced to an Agilent 7890 A GC. An Agilent Technologies analytical capillary column (HP-5MS; $30 \mathrm{~m} \times 250 \mu \mathrm{m} \times 0.25 \mu \mathrm{m}$ film thickness) was used for GC separation, with helium (99.9999\%) as the carrier gas at a constant flow rate of $1.2 \mathrm{~mL} / \mathrm{min}$. The column temperature was initially set at $50{ }^{\circ} \mathrm{C}$ and held for $1 \mathrm{~min}$, then increased to $130{ }^{\circ} \mathrm{C}$ (and held for $1 \mathrm{~min}$ ) at a rate of $30{ }^{\circ} \mathrm{C} / \mathrm{min}$, then increased to $250{ }^{\circ} \mathrm{C}$ at a rate of $5{ }^{\circ} \mathrm{C} / \mathrm{min}$, and finally increased to $290^{\circ} \mathrm{C}$ at a rate of $10^{\circ} \mathrm{C} / \mathrm{min}$, which was held for $5 \mathrm{~min}$. The temperature of the injector port was $250{ }^{\circ} \mathrm{C}$, and a volume of $1 \mu \mathrm{L}$ was injected in splitless mode. The total running time was $38 \mathrm{~min}$.

The mass spectrometer was operated in electron ionization mode $(70 \mathrm{eV})$. The default instrument settings of a collision gas flow for $\mathrm{N}_{2}$ of $1.5 \mathrm{~mL} / \mathrm{min}$ and $\mathrm{He}$ of $2.25 \mathrm{~mL} / \mathrm{min}$, and a quadrupole temperature of $150{ }^{\circ} \mathrm{C}$, were used in all the MS/MS experiments. The detector voltage was automatically set by the instrument after automated MS/MS tuning, which was typically $1250 \mathrm{~V}$. A full autotune of the mass spectrometer, using the default parameters of the instrument, was performed before each sequence. Agilent MassHunter was used for instrument control and data acquisition/processing. For the final multiple reaction monitoring (MRM) acquisition method, two ion transitions at the experimentally optimized collision energy (CE) were monitored for each analyte. Both pairs of the MRM transitions were used for confirmation analysis, and the most sensitive transitions were selected for quantification analysis to obtain better separation efficiency. Table 1 summarizes the optimized MS/MS conditions for the individual analytes and their typical retention times (RT). 
Table 1. MRM parameters of 72 pesticides in wine determined by GC-MS/MS.

\begin{tabular}{|c|c|c|c|c|}
\hline No. & Pesticide & RT (min) & $\begin{array}{l}\text { Quantification } \\
\text { Transition }^{\text {a }}\end{array}$ & $\begin{array}{l}\text { Confirmation } \\
\text { Transition a }\end{array}$ \\
\hline 1 & dichlorvos & 5.22 & $109 \rightarrow 79(5)$ & $185 \rightarrow 93(10)$ \\
\hline 2 & $o$-phenylphenol & 10.21 & $170 \rightarrow 169(10)$ & $169 \rightarrow 141(10)$ \\
\hline 3 & sulfotep-ethyl & 13.31 & $322 \rightarrow 146(25)$ & $322 \rightarrow 65(40)$ \\
\hline 4 & phorate & 13.41 & $121 \rightarrow 65(10)$ & $260 \rightarrow 75(5)$ \\
\hline 5 & simazine & 14.32 & $201 \rightarrow 172(10)$ & $186 \rightarrow 68$ (25) \\
\hline 6 & thiabendazole & 14.33 & $201 \rightarrow 130(25)$ & $201 \rightarrow 174(15)$ \\
\hline 7 & carbofuran & 14.51 & $164 \rightarrow 149$ (10) & $164 \rightarrow 131(20)$ \\
\hline 8 & indoxacarb & 14.51 & $218 \rightarrow 203$ & $264 \rightarrow 176$ (15) \\
\hline 9 & atrazine & 14.52 & $171.9 \rightarrow 69(15)$ & $172 \rightarrow 43(30)$ \\
\hline 10 & acephate & 14.52 & $136 \rightarrow 94(10)$ & $136 \rightarrow 42(10)$ \\
\hline 11 & clomazone & 14.60 & $124.9 \rightarrow 89(20)$ & $204 \rightarrow 107(20)$ \\
\hline 12 & terbufos & 15.01 & $231 \rightarrow 129$ & $231 \rightarrow 175$ (10) \\
\hline 13 & pyrimethanil & 15.33 & $198 \rightarrow 118(25)$ & $198 \rightarrow 156(25)$ \\
\hline 14 & acetochlor & 17.18 & $223 \rightarrow 132(20)$ & $146 \rightarrow 118(10)$ \\
\hline 15 & methyl parathion & 17.23 & $263 \rightarrow 109(15)$ & $263 \rightarrow 79(30)$ \\
\hline 16 & dimethoate & 17.36 & $125 \rightarrow 79$ & $125 \rightarrow 93(10)$ \\
\hline 17 & tolclofos-methyl & 17.36 & $265 \rightarrow 250(15)$ & $265 \rightarrow 93(25)$ \\
\hline 18 & iprovalicarb I & 17.88 & $158 \rightarrow 98(10)$ & $158 \rightarrow 116(10)$ \\
\hline 19 & fenitrothion & 18.29 & $277 \rightarrow 260$ & $277 \rightarrow 109$ \\
\hline 20 & ethofumesate & 18.44 & $286 \rightarrow 207(5)$ & $286 \rightarrow 179(15)$ \\
\hline 21 & carbosulfan & 18.74 & $160 \rightarrow 104(10)$ & $160 \rightarrow 57(15)$ \\
\hline 22 & malathion & 18.76 & $173 \rightarrow 99(15)$ & $173 \rightarrow 117(15)$ \\
\hline 23 & metolachlor & 18.87 & $162 \rightarrow 133$ (15) & $162.2 \rightarrow 132(25)$ \\
\hline 24 & fenthion & 18.99 & $278 \rightarrow 109(10)$ & $278 \rightarrow 125$ (15) \\
\hline 25 & diethofencarb & 19.01 & $267 \rightarrow 225$ & $196 \rightarrow 168$ \\
\hline 26 & chlorpyrifos & 19.06 & $314 \rightarrow 258$ (15) & $314 \rightarrow 286$ (15) \\
\hline 27 & triadimefon & 19.26 & $208 \rightarrow 181(10)$ & $208 \rightarrow 111$ (15) \\
\hline 28 & isocarbophos & 19.34 & $136 \rightarrow 108(14)$ & $230 \rightarrow 212$ \\
\hline 29 & cyprodinil & 19.977 & $225 \rightarrow 224(10)$ & $224 \rightarrow 208(20)$ \\
\hline 30 & metazachlor & 20.18 & $209 \rightarrow 132(20)$ & $133 \rightarrow 117(25)$ \\
\hline 31 & pendimethalin & 20.25 & $252 \rightarrow 162(10)$ & $252 \rightarrow 161(20)$ \\
\hline 32 & chlorfenvinphos & 20.68 & $267 \rightarrow 159$ (20) & $267 \rightarrow 81$ \\
\hline 33 & fipronil & 20.78 & $367 \rightarrow 213$ & $367 \rightarrow 228$ (30) \\
\hline 34 & procymidone & 20.90 & $283 \rightarrow 96(10)$ & $283 \rightarrow 255(10)$ \\
\hline 35 & vinclozolin & 20.90 & $212 \rightarrow 145$ (15) & $212 \rightarrow 172(25)$ \\
\hline 36 & methidathion & 21.18 & $145 \rightarrow 85$ (5) & $145 \rightarrow 58$ (15) \\
\hline 37 & butachlor & 21.76 & $237 \rightarrow 160$ & $188.1 \rightarrow 160(10)$ \\
\hline 38 & flutriafol & 21.94 & $164 \rightarrow 109$ (20) & $219 \rightarrow 123$ (15) \\
\hline 39 & carbaryl & 22.04 & $144 \rightarrow 116$ (15) & $144 \rightarrow 114$ \\
\hline 40 & napropamide & 22.04 & $128 \rightarrow 72(10)$ & $271 \rightarrow 128$ \\
\hline 41 & hexaconazole & 22.14 & $213.9 \rightarrow 172(20)$ & $214 \rightarrow 159$ (20) \\
\hline 42 & profenofos & 22.40 & $208 \rightarrow 63$ (35) & $208 \rightarrow 98(25)$ \\
\hline 43 & oxadiazon & 22.72 & $175 \rightarrow 112(15)$ & $302 \rightarrow 175$ (13) \\
\hline 44 & iprovalicarb II & 22.73 & $158 \rightarrow 98(10)$ & $158 \rightarrow 116(10)$ \\
\hline 45 & carboxin & 22.76 & $235 \rightarrow 143$ (5) & $144 \rightarrow 87$ \\
\hline 46 & oxyfluorfen & 22.97 & $252 \rightarrow 252$ (5) & $252 \rightarrow 196(20)$ \\
\hline 47 & flusilazole & 23.05 & $233 \rightarrow 152(20)$ & $233 \rightarrow 165(20)$ \\
\hline 48 & kresoxim-methyl & 23.13 & $206 \rightarrow 116$ & $206 \rightarrow 131(10)$ \\
\hline 49 & metalaxyl & 23.13 & $206 \rightarrow 132(5)$ & $206 \rightarrow 162(20)$ \\
\hline 50 & diniconazole & 24.11 & $268 \rightarrow 232$ (15) & $270 \rightarrow 234(15)$ \\
\hline 51 & triazophos & 24.72 & $161 \rightarrow 134$ & $257 \rightarrow 162(5)$ \\
\hline 52 & propiconazole I & 25.27 & $259 \rightarrow 173$ (15) & $261 \rightarrow 175$ \\
\hline 53 & propiconazole II & 25.46 & $259 \rightarrow 69(12)$ & $259 \rightarrow 191(5)$ \\
\hline 54 & propyzamide & 25.47 & $173 \rightarrow 145$ (20) & $175 \rightarrow 147(20)$ \\
\hline 55 & diclofop-methyl & 25.96 & $253 \rightarrow 162$ (15) & $340 \rightarrow 253$ (15) \\
\hline 56 & epoxiconazole & 26.55 & $192 \rightarrow 138(10)$ & $192 \rightarrow 157(5)$ \\
\hline
\end{tabular}


Table 1. Cont.

\begin{tabular}{|c|c|c|c|c|}
\hline No. & Pesticide & $\mathrm{RT}$ (min) & $\begin{array}{l}\text { Quantification } \\
\text { Transition }^{\text {a }}\end{array}$ & $\begin{array}{c}\text { Confirmation } \\
\text { Transition }^{\mathrm{a}}\end{array}$ \\
\hline 57 & iprodione & 26.85 & $314 \rightarrow 245$ (10) & $314 \rightarrow 271(20)$ \\
\hline 58 & cypermethrin-I & 27.33 & $181 \rightarrow 152$ & $181 \rightarrow 127(35)$ \\
\hline 59 & bifenthrin & 27.33 & $181 \rightarrow 165$ (25) & $181 \rightarrow 166$ \\
\hline 60 & bifenox & 27.77 & $311 \rightarrow 279(10)$ & $311 \rightarrow 216(20)$ \\
\hline 61 & pyriproxyfen & 28.61 & $136 \rightarrow 78$ & - \\
\hline 62 & cypermethrin II & 28.91 & $181 \rightarrow 152$ (30) & $181 \rightarrow 127$ \\
\hline 63 & beta-cypermethrin & 28.92 & $181 \rightarrow 152$ & $181 \rightarrow 127$ (35) \\
\hline 64 & cypermethrin III & 29.26 & $181 \rightarrow 152$ & $181 \rightarrow 127$ \\
\hline 65 & permethrin I & 30.58 & $183 \rightarrow 153(20)$ & $183 \rightarrow 168(20)$ \\
\hline 66 & pyridaben & 30.52 & $147 \rightarrow 117$ & $147 \rightarrow 132(10)$ \\
\hline 67 & permethrin II & 30.37 & $183 \rightarrow 115$ (25) & $183 \rightarrow 77(30)$ \\
\hline 68 & cypermethrin IV & 30.58 & $181 \rightarrow 152$ & $181 \rightarrow 127(35)$ \\
\hline 69 & difenoconazole & 33.61 & $323 \rightarrow 265(10)$ & $265 \rightarrow 139(25)$ \\
\hline 70 & azoxystrobin & 34.40 & $344 \rightarrow 329$ (15) & $253 \rightarrow 172(20)$ \\
\hline 71 & deltamethrin I & 33.62 & $181 \rightarrow 152(25)$ & $253 \rightarrow 172(10)$ \\
\hline 72 & deltamethrin II & 33.92 & $181 \rightarrow 152$ (25) & $253 \rightarrow 172(10)$ \\
\hline
\end{tabular}

a Collision energy $(\mathrm{eV})$ is given in parentheses.

\subsection{Sample Preparation}

A QuEChERS-based approach was adapted to isolate the 72 analytes in the wine samples. The samples were obtained from a local supermarket and homogenized with a blender for $1 \mathrm{~min}$ at room temperature. For the determination of the recovery, the homogenized samples $(10.0 \pm 0.1 \mathrm{~g})$ were spiked by adding the standard stock solutions at three concentrations: $0.01,0.05$ and $0.1 \mathrm{mg} / \mathrm{kg}$. The spiked samples were set aside for 30 min before extraction.

An amount $(10.0 \pm 0.1 \mathrm{~g})$ of each wine sample was weighed into a $50 \mathrm{~mL}$ centrifuge tube and $10 \mathrm{~mL}$ of acetonitrile was added. The resulting solution was shaken using a vortex for $1 \mathrm{~min}$; then, $1 \mathrm{~g}$ of sodium chloride and $4 \mathrm{~g}$ of anhydrous magnesium sulfate were added. The tube was cooled immediately to room temperature in an ice-water bath. The centrifuge tube was shaken vigorously for $1 \mathrm{~min}$ to prevent salt agglomeration before centrifugation at $3800 \mathrm{rpm}$ for $5 \mathrm{~min}$. The $1 \mathrm{~mL}$ supernatant was used for further $\mathrm{m}-\mathrm{PFC}$.

\section{4. $m$-PFC Procedures}

The m-PFC procedure involved the following steps (shown in Figure 1): $1 \mathrm{~mL}$ of the supernatant was introduced into a $2.0 \mathrm{~mL}$ centrifuge tube. The sorbents (including $150 \mathrm{mg}$ of anhydrous $\mathrm{MgSO}_{4}$ ) in the column were adopted from the optimized d-SPE sorbents. As shown in Figure 1, the syringe needle was kept under the surface of the extract; then, the syringe piston was pulled and pushed to let the extracts pass through the sorbents for the purpose of cleaning. Finally, the layer was filtered through a $0.22 \mu \mathrm{m}$ filter membrane. The extract was placed into a GC vial for chromatographic analysis.

\subsection{Method Performance}

The analytical method was validated according to the following parameters: the linearity, limit of quantification (LOQ), limit of detection (LOD), precision and accuracy. The test of linearity used matrix-matched calibration by analyzing samples of red wine and white wine. The precision and accuracy experiments were carried out in five replicates, each at three fortification levels $(0.01,0.05$ and $0.1 \mathrm{mg} / \mathrm{kg})$ for the sample matrix. According to SANTE/12682/2019 [65], the LOQs were determined as the concentrations of analyte giving a signal-to-noise ratio $(\mathrm{S} / \mathrm{N}) \geq 3$ and analyte peaks from both product ions in the extracted ion chromatograms must fully overlap. Ion ratio from sample extracts should be within $\pm 30 \%$ (relative) of average of calibration standards from the same sequence. 


\subsection{Analysis of Grape Wine Samples}

Grape wine samples, including fifty red grape wines and twenty white grape wines, were purchased at supermarkets in Beijing and they belonged to several vintages between 2011 and 2018. Seventy samples were produced in wineries from different countries: China (42), France (7), Spain (5), Portugal (5), Italy (4), Australia (4) and the USA (3). The alcoholic strength ranged from $10 \%$ to $15 \%$ (Alc/vol). Bottled wines were stored in their original packaging at $5{ }^{\circ} \mathrm{C}$.

\section{Results and Discussion}

\subsection{Amount of the MWCNTs}

After the analytes had been extracted using $10 \mathrm{~mL}$ of acetonitrile, followed by the partitioning of the analyte molecules in an organic solvent in the presence of a salt mixture (the salting-out effect), $1 \mathrm{~mL}$ of the acetonitrile phase was further cleaned by the m-PFC procedure. Zhao et al. [62] found that different amounts of MWCNT sorbents had a significant influence on the purification and recovery of the pesticide extracts. To evaluate the effect of this parameter, different amounts of MWCNT were investigated in the same procedure. The amount of sorbent material was progressively increased from $5 \mathrm{mg}$ to 10 , 15 and $20 \mathrm{mg}$. The experiment was performed using $1 \mathrm{~mL}$ of the acetonitrile extract at a spiking level of $0.1 \mathrm{mg} / \mathrm{kg}$ and it was then cleaned by the m-PFC method with different amounts of MWCNT. The recovery of most of the analytes increased with the amount of MWCNTs and the results were within an acceptable range: $70-120 \%$ for red wine. As shown in Figure 2, upon increasing the amount of MWCNTs from 5 to $10 \mathrm{mg}$, the recovery levels for epoxiconazole, profenofos, azoxystrobin and bifenthrin remained acceptable (70-103\%). However, the recovery decreased to 33-69\% when the amount of MWCNTs was increased to 15 and $20 \mathrm{mg}$. In addition, although better recovery was achieved with $5 \mathrm{mg}$ of MWCNT materials, the performance was not as good as that with $10 \mathrm{mg}$, and there was more chromatography interference when $5 \mathrm{mg}$ was used. The recovery was also acceptable with $10 \mathrm{mg}$ of MWCNTs. Consequently, $10 \mathrm{mg}$ ( $1 \mathrm{~mL}$ of the extract) was used as the optimum amount for $\mathrm{m}$-PFC in further studies, since acceptable recovery and good cleanup performance was obtained with this amount.

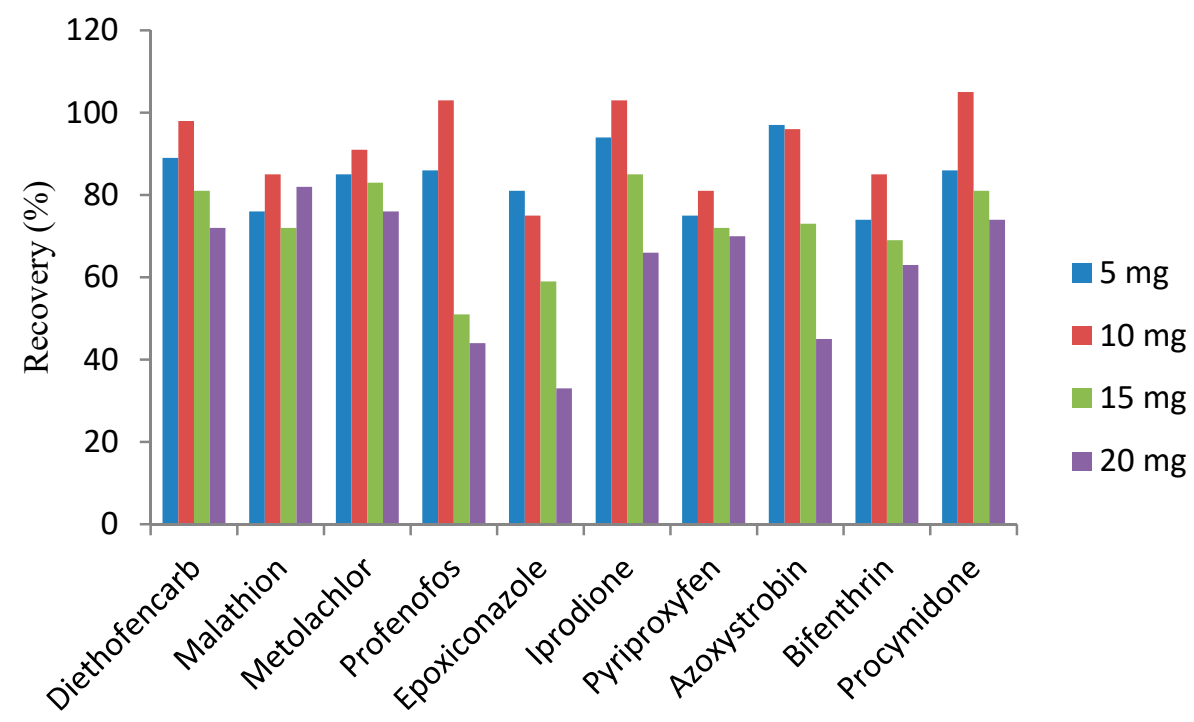

Figure 2. Effects of the amount of MWCNTs on recovery.

\subsection{Optimization of the m-PFC Procedure Cycle Times}

In order to obtain the best recovery and cleanup performance, the cycles of pulling and pushing during the $\mathrm{m}-\mathrm{PFC}$ procedure were optimized. The recovery was acceptable with one and two cycles of pulling and pushing, but the cleanup performance was not as 
good as that with three cycles and there was more chromatography interference for one or two pull-push cycles. In addition, four cycles were also tested, but there was no significant difference in cleanup performance from that with three cycles. As a result, three cycles of pulling and pushing were chosen for the optimized m-PFC procedure. Figure 3 shows the purification effects of different cleanup cycles.

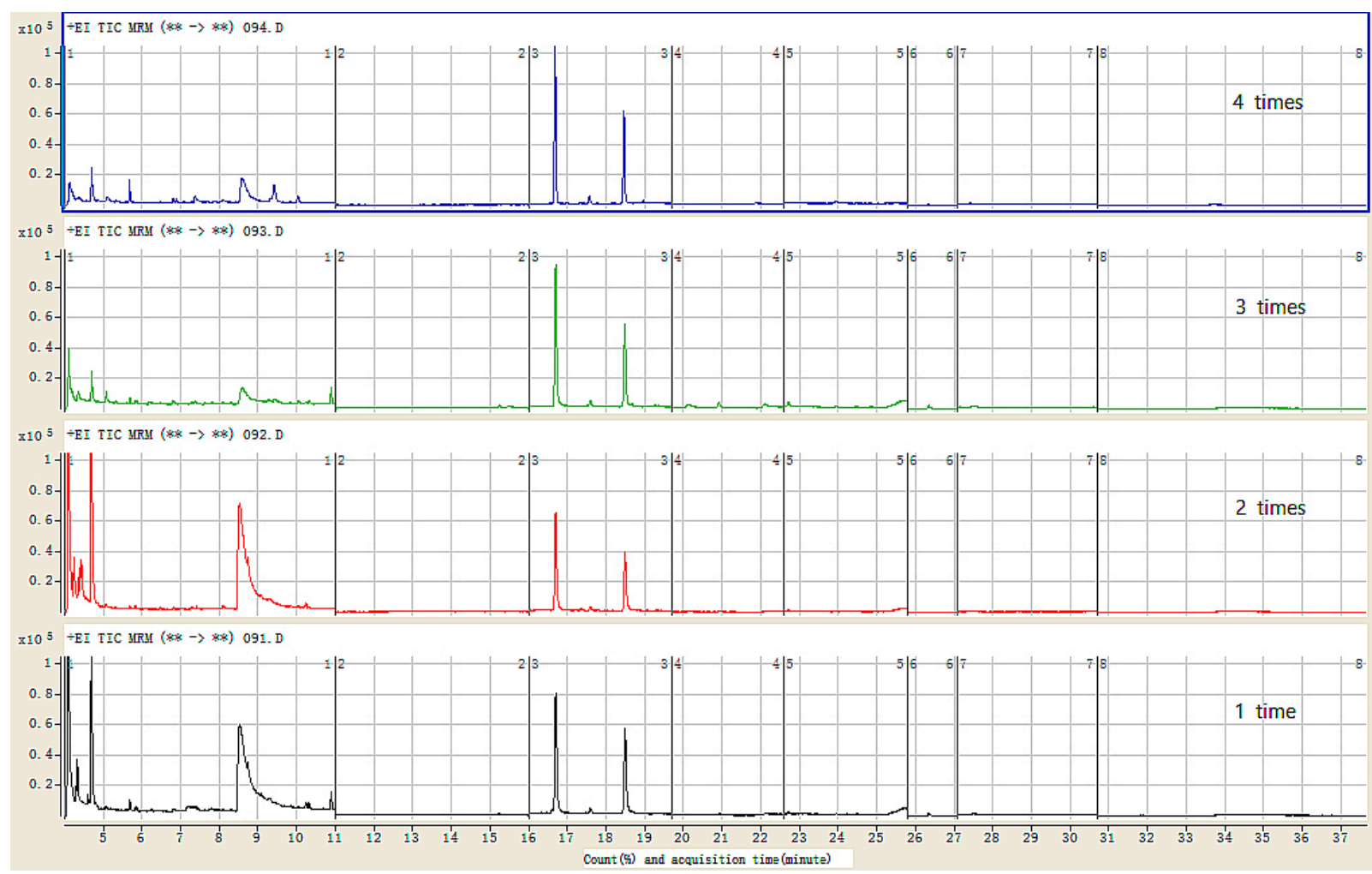

Figure 3. The optimization of m-PFC procedure cycle times by pulling and pushing to red wine blank samples (the initial value for each cleanup sample: $2 \mathrm{~mL}$ ).

\subsection{Validation of the Method \\ 3.3.1. Linearity and Matrix Effects}

Linearity was studied in the range of $0.002-0.1 \mathrm{mg} / \mathrm{L}$ for all the pesticides at five calibration levels $(0.002,0.005,0.01,0.02,0.05$ and $0.1 \mathrm{mg} / \mathrm{L})$ by a matrix-matched standard calibration in blank extracts of red wine and white wine. Linear calibration graphs were constructed by plotting analyte concentrations versus the relative peak areas of the calibration standards. The linearity values, calculated as the determination coefficients $\left(R^{2}\right)$ for each pesticide from the matrix-matched calibration (m-PFC cleanup) plots, are shown in Table 2. The quantitative results of the detection method greatly depend on its calibration. Both pure solvent-based as well as matrix-matched calibrations gave $\mathrm{R}^{2}$ values better than 0.985 . This was remarkable, considering the complexity of the matrices. The matrix effects (ME) were evaluated in terms of slope ratios: $100 \times(1$-slope acetonitrile/slope matrix) $[62,66]$.

The matrix effects include enhancement or suppression effects, so the concentration results obtained can be erroneous, depending on the solvent calibration curves [18]. To examine the matrix effects, matrix-matched standards were compared with solvent standards. Table 2 summarizes the results. In our work, it was considered that, if the value was in the range of -10 to $10 \%$, the matrix effect could be ignored; if the value was lower than $-10 \%$ or higher than $10 \%$, this showed a matrix-suppression or an enhancement effect, respectively $[62,66]$. The results show that, in red and white wine, 45 and 25 of the pesticides presented an enhancement effect $(\mathrm{ME}>0)$, respectively, and the other 27 
and 47 of the pesticides showed a suppression effect (ME $<0)$, respectively; 44 and 34 of the pesticides expressed distinct matrix-suppression and enhancement effects. Therefore, for more accurate results, validation experiments were performed for pesticide residue concentrations in non-compliant samples, calculated using matrix-matched calibration standards and excluding any influence produced by matrix effects, as recommended in SANTE/12682/2019 [65]. In order to overcome the adverse impact of matrix effects on the quantified results, we calibrated the sample results with matrix-matched standards to guarantee the correct quantification of the pesticide concentrations in real samples.

Table 2. Linearity parameters (range, slope and $\mathrm{R}^{2}$ ) obtained by using standards in acetonitrile and by matching, as well as matrix effects measured as $100 \times(1$-slope acetonitrile/slope matrix).

\begin{tabular}{|c|c|c|c|c|c|c|c|c|c|}
\hline \multirow[b]{2}{*}{ Pesticide } & \multirow{2}{*}{$\begin{array}{c}\text { Linearity } \\
\text { Range } \\
\text { (mg/kg) }\end{array}$} & \multicolumn{2}{|c|}{ Acetonitrile } & \multicolumn{3}{|c|}{ Red Wine } & \multicolumn{3}{|c|}{ White Wine } \\
\hline & & Slope & $\mathbf{R}^{2}$ & Slope & $\mathbf{R}^{2}$ & $\begin{array}{c}\text { Matrix } \\
\text { Effect, \% }\end{array}$ & Slope & $\mathrm{R}^{2}$ & $\begin{array}{c}\text { Matrix } \\
\text { Effect, \% }\end{array}$ \\
\hline dichlorvos & $0.002-0.1$ & $9.6 \times 10^{4}$ & 0.9924 & $1.1 \times 10^{5}$ & 0.9977 & 9.4 & $9.5 \times 10^{4}$ & 0.9999 & -1.7 \\
\hline$o$-phenylphenol & $0.002-0.1$ & $6.8 \times 10^{5}$ & 0.9989 & $8.5 \times 10^{5}$ & 0.9912 & 19.5 & $7.0 \times 10^{5}$ & 0.9958 & 2.2 \\
\hline sulfotep-ethyl & $0.002-0.1$ & $3.3 \times 10^{5}$ & 0.9916 & $3.6 \times 10^{5}$ & 0.9982 & 8.5 & $3.4 \times 10^{5}$ & 0.9920 & 3.6 \\
\hline phorate & $0.002-0.1$ & $2.2 \times 10^{5}$ & 0.9897 & $2.3 \times 10^{5}$ & 0.9899 & 6.1 & $2.3 \times 10^{5}$ & 0.9957 & 5.9 \\
\hline simazine & $0.002-0.1$ & $3.4 \times 10^{4}$ & 0.9878 & $3.9 \times 10^{4}$ & 0.9985 & 12.5 & $3.1 \times 10^{4}$ & 0.9990 & -7.4 \\
\hline thiabendazole & $0.005-0.1$ & $6.8 \times 10^{3}$ & 0.9855 & $5.9 \times 10^{3}$ & 0.9959 & -14.9 & $6.6 \times 10^{3}$ & 0.9956 & -3.8 \\
\hline carbofuran & $0.002-0.1$ & $3.1 \times 10^{5}$ & 0.9968 & $3.3 \times 10^{5}$ & 0.9986 & 8.1 & $3.2 \times 10^{5}$ & 0.9921 & 4.5 \\
\hline indoxacarb & $0.005-0.1$ & $3.0 \times 10^{3}$ & 0.9997 & $2.8 \times 10^{3}$ & 0.9922 & -5.9 & $2.5 \times 10^{3}$ & 0.9894 & -17.0 \\
\hline atrazine & $0.002-0.1$ & $1.7 \times 10^{4}$ & 0.9989 & $2.0 \times 10^{4}$ & 0.9954 & 11.1 & $1.5 \times 10^{4}$ & 0.9853 & -15.3 \\
\hline acephate & $0.005-0.1$ & $3.3 \times 10^{3}$ & 0.9991 & $3.8 \times 10^{3}$ & 0.9858 & 13.6 & $3.4 \times 10^{3}$ & 0.9887 & 2.6 \\
\hline clomazone & $0.002-0.1$ & $3.1 \times 10^{5}$ & 0.9926 & $3.7 \times 10^{5}$ & 0.9495 & 14.8 & $3.2 \times 10^{5}$ & 0.9885 & 3.2 \\
\hline terbufos & $0.002-0.1$ & $2.1 \times 10^{4}$ & 0.9917 & $2.5 \times 10^{4}$ & 0.9916 & 17.4 & $2.5 \times 10^{4}$ & 0.9977 & 17.1 \\
\hline pyrimethanil & $0.002-0.1$ & $1.7 \times 10^{5}$ & 0.9957 & $1.5 \times 10^{5}$ & 0.9987 & -10.1 & $1.6 \times 10^{5}$ & 0.9986 & -6.9 \\
\hline acetochlor & $0.002-0.1$ & $8.8 \times 10^{4}$ & 0.9935 & $1.2 \times 10^{5}$ & 0.9984 & 24.1 & $9.5 \times 10^{4}$ & 0.9910 & 6.9 \\
\hline methyl parathion & $0.002-0.1$ & $3.8 \times 10^{5}$ & 0.9996 & $4.1 \times 10^{5}$ & 0.9941 & 7.2 & $3.7 \times 10^{5}$ & 0.9915 & -2.1 \\
\hline dimethoate & $0.002-0.1$ & $1.0 \times 10^{6}$ & 0.9919 & $9.3 \times 10^{5}$ & 0.9896 & -7.2 & $8.9 \times 10^{5}$ & 0.9994 & -12.9 \\
\hline tolclofos-methyl & $0.002-0.1$ & $5.0 \times 10^{6}$ & 0.9928 & $6.0 \times 10^{6}$ & 0.9959 & 16.7 & $5.4 \times 10^{6}$ & 0.9995 & 7.4 \\
\hline iprovalicarb I & $0.002-0.1$ & $5.5 \times 10^{3}$ & 0.9937 & $6.8 \times 10^{3}$ & 0.9866 & 18.7 & $4.9 \times 10^{3}$ & 0.9956 & -12.8 \\
\hline fenitrothion & $0.002-0.1$ & $8.4 \times 10^{4}$ & 0.9930 & $9.5 \times 10^{4}$ & 0.9859 & 12.3 & $8.5 \times 10^{4}$ & 0.9943 & 1.9 \\
\hline ethofumesate & $0.002-0.1$ & $2.1 \times 10^{5}$ & 0.9954 & $2.2 \times 10^{5}$ & 0.9973 & 5.8 & $1.9 \times 10^{5}$ & 0.9899 & -11.2 \\
\hline carbosulfan & $0.002-0.1$ & $9.2 \times 10^{2}$ & 0.9919 & $1.1 \times 10^{3}$ & 0.9928 & 15.4 & $1.1 \times 10^{3}$ & 0.9945 & 15.6 \\
\hline malathion & $0.002-0.1$ & $2.8 \times 10^{5}$ & 0.9966 & $3.1 \times 10^{5}$ & 0.9959 & 10.4 & $2.5 \times 10^{5}$ & 0.9948 & -11.9 \\
\hline metolachlor & $0.002-0.1$ & $4.5 \times 10^{5}$ & 0.9987 & $5.5 \times 10^{5}$ & 0.9866 & 18.2 & $4.5 \times 10^{5}$ & 0.9942 & -0.4 \\
\hline fenthion & $0.002-0.1$ & $1.4 \times 10^{5}$ & 0.9934 & $1.6 \times 10^{5}$ & 0.9967 & 7.5 & $1.4 \times 10^{5}$ & 0.9984 & -3.5 \\
\hline diethofencarb & $0.002-0.1$ & $3.7 \times 10^{5}$ & 0.9997 & $4.0 \times 10^{5}$ & 0.9819 & 6.5 & $3.9 \times 10^{5}$ & 0.9894 & 5.6 \\
\hline chlorpyrifos & $0.002-0.1$ & $1.9 \times 10^{5}$ & 0.9942 & $2.2 \times 10^{5}$ & 0.9925 & 15.7 & $1.9 \times 10^{5}$ & 0.9948 & 1.3 \\
\hline triadimefon & $0.002-0.1$ & $1.2 \times 10^{5}$ & 0.9998 & $9.7 \times 10^{4}$ & 0.9937 & -24.1 & $1.1 \times 10^{5}$ & 0.9951 & -9.3 \\
\hline isocarbophos & $0.002-0.1$ & $3.3 \times 10^{5}$ & 0.9929 & $3.5 \times 10^{5}$ & 0.9958 & 5.8 & $3.4 \times 10^{5}$ & 0.9935 & 4.2 \\
\hline cyprodinil & $0.002-0.1$ & $9.5 \times 10^{5}$ & 0.9999 & $8.6 \times 10^{5}$ & 0.9863 & -10.4 & $7.7 \times 10^{5}$ & 0.9864 & -23.1 \\
\hline metazachlor & $0.002-0.1$ & $1.5 \times 10^{5}$ & 0.9991 & $1.4 \times 10^{5}$ & 0.9988 & -9.2 & $1.8 \times 10^{5}$ & 0.9987 & 14.0 \\
\hline pendimethalin & $0.002-0.1$ & $1.0 \times 10^{5}$ & 0.9894 & $1.0 \times 10^{5}$ & 0.9979 & 2.2 & $1.2 \times 10^{5}$ & 0.9839 & 15.1 \\
\hline chlorfenvinphos & $0.002-0.1$ & $1.0 \times 10^{5}$ & 0.9931 & $1.2 \times 10^{5}$ & 0.9890 & 12.6 & $8.9 \times 10^{4}$ & 0.9847 & -14.9 \\
\hline fipronil & $0.002-0.1$ & $5.2 \times 10^{4}$ & 0.9968 & $6.5 \times 10^{4}$ & 0.9881 & 19.0 & $4.9 \times 10^{4}$ & 0.9850 & -6.6 \\
\hline procymidone & $0.002-0.1$ & $2.2 \times 10^{5}$ & 0.9914 & $2.1 \times 10^{5}$ & 0.9959 & -3.2 & $1.8 \times 10^{5}$ & 0.9854 & -23.2 \\
\hline vinclozolin & $0.002-0.1$ & $6.6 \times 10^{3}$ & 0.9934 & $6.0 \times 10^{3}$ & 0.9948 & -10.5 & $5.9 \times 10^{3}$ & 0.9994 & -13.2 \\
\hline methidathion & $0.002-0.1$ & $4.3 \times 10^{5}$ & 0.9895 & $4.7 \times 10^{5}$ & 0.9939 & 9.2 & $3.8 \times 10^{5}$ & 0.9885 & -11.3 \\
\hline butachlor & $0.002-0.1$ & $7.5 \times 10^{4}$ & 0.9916 & $9.1 \times 10^{4}$ & 0.9957 & 18.0 & $7.3 \times 10^{4}$ & 0.9887 & -1.7 \\
\hline flutriafol & $0.002-0.1$ & $1.3 \times 10^{5}$ & 0.9967 & $1.4 \times 10^{5}$ & 0.9955 & 10.7 & $1.2 \times 10^{5}$ & 0.9916 & -8.6 \\
\hline carbaryl & $0.005-0.1$ & $2.7 \times 10^{4}$ & 0.9958 & $2.4 \times 10^{4}$ & 0.9889 & -13.9 & $2.6 \times 10^{4}$ & 0.9943 & -6.9 \\
\hline
\end{tabular}


Table 2. Cont.

\begin{tabular}{|c|c|c|c|c|c|c|c|c|c|}
\hline \multirow[b]{2}{*}{ Pesticide } & \multirow{2}{*}{$\begin{array}{c}\text { Linearity } \\
\text { Range } \\
\text { (mg/kg) }\end{array}$} & \multicolumn{2}{|c|}{ Acetonitrile } & \multicolumn{3}{|c|}{ Red Wine } & \multicolumn{3}{|c|}{ White Wine } \\
\hline & & Slope & $\mathbf{R}^{2}$ & Slope & $\mathbf{R}^{2}$ & $\begin{array}{c}\text { Matrix } \\
\text { Effect, \% }\end{array}$ & Slope & $\mathbf{R}^{2}$ & $\begin{array}{c}\text { Matrix } \\
\text { Effect, \% }\end{array}$ \\
\hline napropamide & $0.002-0.1$ & $1.7 \times 10^{5}$ & 0.9938 & $1.7 \times 10^{5}$ & 0.9998 & 1.5 & $1.6 \times 10^{5}$ & 0.9979 & -6.3 \\
\hline hexaconazole & $0.002-0.1$ & $5.1 \times 10^{4}$ & 0.9996 & $4.6 \times 10^{4}$ & 0.9964 & -12.0 & $4.8 \times 10^{4}$ & 0.9948 & -6.7 \\
\hline profenofos & $0.002-0.1$ & $1.6 \times 10^{4}$ & 0.9949 & $2.1 \times 10^{4}$ & 0.9962 & 25.3 & $1.8 \times 10^{4}$ & 0.9999 & 12.3 \\
\hline oxadiazon & $0.002-0.1$ & $3.0 \times 10^{5}$ & 0.9925 & $3.0 \times 10^{5}$ & 0.9969 & -0.8 & $2.5 \times 10^{5}$ & 0.9948 & -18.9 \\
\hline iprovalicarb II & $0.005-0.1$ & $1.1 \times 10^{3}$ & 0.9939 & $9.9 \times 10^{2}$ & 0.9928 & -5.7 & $9.3 \times 10^{2}$ & 0.9972 & -12.7 \\
\hline carboxin & $0.002-0.1$ & $2.5 \times 10^{5}$ & 0.9916 & $3.4 \times 10^{5}$ & 0.9896 & 28.6 & $2.4 \times 10^{5}$ & 1.0000 & -4.2 \\
\hline oxyfluorfen & $0.002-0.1$ & $2.3 \times 10^{5}$ & 0.9984 & $2.6 \times 10^{5}$ & 0.9927 & 11.5 & $2.0 \times 10^{5}$ & 0.9942 & -17.5 \\
\hline flusilazole & $0.002-0.1$ & $1.1 \times 10^{5}$ & 0.9956 & $8.8 \times 10^{4}$ & 0.9990 & -24.3 & $9.5 \times 10^{4}$ & 0.9940 & -15.0 \\
\hline kresoxim-methyl & $0.002-0.1$ & $1.9 \times 10^{5}$ & 0.9942 & $1.6 \times 10^{5}$ & 0.9792 & -19.6 & $1.8 \times 10^{5}$ & 0.9998 & -10.1 \\
\hline metalaxyl & $0.002-0.1$ & $1.2 \times 10^{5}$ & 0.9967 & $9.7 \times 10^{4}$ & 0.9963 & -20.1 & $9.3 \times 10^{4}$ & 0.9965 & -25.2 \\
\hline diniconazole & $0.002-0.1$ & $1.5 \times 10^{5}$ & 0.9924 & $1.3 \times 10^{5}$ & 0.9928 & -21.4 & $1.4 \times 10^{5}$ & 0.9971 & -14.1 \\
\hline triazophos & $0.002-0.1$ & $9.2 \times 10^{4}$ & 0.9913 & $9.2 \times 10^{4}$ & 0.9969 & -0.8 & $9.1 \times 10^{4}$ & 0.9857 & -2.0 \\
\hline Propiconazole I & $0.002-0.1$ & $9.4 \times 10^{4}$ & 0.9957 & $9.4 \times 10^{4}$ & 0.9942 & -0.8 & $9.1 \times 10^{4}$ & 0.9920 & -3.7 \\
\hline propiconazole II & $0.002-0.1$ & $2.1 \times 10^{5}$ & 0.9962 & $2.2 \times 10^{5}$ & 0.9967 & 2.5 & $1.9 \times 10^{5}$ & 0.9854 & -10.3 \\
\hline propyzamide & $0.002-0.1$ & $5.5 \times 10^{5}$ & 0.9938 & $4.0 \times 10^{5}$ & 0.9966 & -37.3 & $4.9 \times 10^{5}$ & 0.9801 & -13.0 \\
\hline diclofop-methyl & $0.002-0.1$ & $1.1 \times 10^{5}$ & 0.9989 & $1.3 \times 10^{5}$ & 0.9894 & 18.3 & $1.0 \times 10^{5}$ & 0.9900 & -3.9 \\
\hline epoxiconazole & $0.01-0.1$ & $6.0 \times 10^{4}$ & 0.9937 & $6.4 \times 10^{4}$ & 0.9964 & 5.5 & $5.1 \times 10^{4}$ & 0.9977 & -17.2 \\
\hline iprodione & $0.002-0.1$ & $5.5 \times 10^{4}$ & 0.9988 & $7.3 \times 10^{4}$ & 0.9922 & 24.3 & $5.6 \times 10^{4}$ & 0.9884 & 1.9 \\
\hline cypermethrin-I & $0.002-0.1$ & $2.2 \times 10^{4}$ & 0.9936 & $2.4 \times 10^{4}$ & 0.9960 & 8.4 & $2.1 \times 10^{4}$ & 0.9978 & -4.3 \\
\hline bifenthrin & $0.002-0.1$ & $8.8 \times 10^{5}$ & 0.9942 & $1.0 \times 10^{6}$ & 0.9920 & 12.3 & $8.8 \times 10^{5}$ & 0.9920 & 0.4 \\
\hline bifenox & $0.002-0.1$ & $4.1 \times 10^{4}$ & 0.9969 & $4.9 \times 10^{4}$ & 0.9935 & 16.2 & $5.6 \times 10^{4}$ & 0.9918 & 26.8 \\
\hline pyriproxyfen & $0.002-0.1$ & $2.0 \times 10^{5}$ & 0.9960 & $2.6 \times 10^{5}$ & 0.9919 & 24.4 & $2.0 \times 10^{5}$ & 0.9912 & 3.3 \\
\hline cypermethrin II & $0.005-0.1$ & $5.3 \times 10^{4}$ & 0.9938 & $4.7 \times 10^{4}$ & 0.9933 & -11.8 & $4.2 \times 10^{4}$ & 0.9924 & -25.4 \\
\hline beta-cypermethrin & $0.005-0.1$ & $3.4 \times 10^{4}$ & 0.9962 & $3.7 \times 10^{4}$ & 0.9957 & 9.9 & $3.2 \times 10^{4}$ & 0.9909 & -4.4 \\
\hline cypermethrin III & $0.005-0.1$ & $2.8 \times 10^{4}$ & 0.9973 & $2.8 \times 10^{4}$ & 0.9872 & -1.7 & $2.5 \times 10^{4}$ & 0.9955 & -11.7 \\
\hline permethrin I & $0.005-0.1$ & $3.9 \times 10^{4}$ & 0.9959 & $4.7 \times 10^{4}$ & 0.9868 & 16.0 & $5.0 \times 10^{4}$ & 0.9947 & 21.6 \\
\hline pyridaben & $0.002-0.1$ & $8.0 \times 10^{5}$ & 0.9929 & $1.0 \times 10^{6}$ & 0.9910 & 20.0 & $8.3 \times 10^{5}$ & 0.9948 & 4.0 \\
\hline Permethrin II & $0.005-0.1$ & $2.5 \times 10^{4}$ & 0.9954 & $2.3 \times 10^{4}$ & 0.9925 & -8.1 & $2.8 \times 10^{4}$ & 0.9944 & 10.5 \\
\hline cypermethrin IV & $0.005-0.1$ & $7.7 \times 10^{3}$ & 0.9966 & $9.2 \times 10^{3}$ & 0.9890 & 16.2 & $9.3 \times 10^{3}$ & 0.9978 & 17.0 \\
\hline difenoconazole & $0.002-0.1$ & $5.9 \times 10^{5}$ & 0.9919 & $6.2 \times 10^{5}$ & 0.9887 & 3.9 & $4.6 \times 10^{5}$ & 0.9991 & -28.4 \\
\hline azoxystrobin & $0.005-0.1$ & $2.0 \times 10^{4}$ & 0.9961 & $2.4 \times 10^{4}$ & 0.9921 & 16.2 & $1.6 \times 10^{4}$ & 0.9958 & -26.8 \\
\hline deltamethrin I & $0.002-0.1$ & $3.8 \times 10^{3}$ & 0.9958 & $3.4 \times 10^{3}$ & 0.9858 & -13.1 & $3.6 \times 10^{3}$ & 0.9957 & -6.8 \\
\hline deltamethrin II & $0.002-0.1$ & $5.0 \times 10^{3}$ & 0.9952 & $4.30 \times 10^{3}$ & 0.9853 & -16.1 & $4.20 \times 10^{3}$ & 0.9875 & -18.9 \\
\hline
\end{tabular}

\subsubsection{Recovery and Precision}

The recovery and repeatability of the method were established to evaluate the method's performance. The repeatability and the accuracy of the method were tested by carrying out five consecutive extractions $(n=5)$ of spiked matrices at three concentration levels $(0.01,0.05$ and $0.1 \mathrm{mg} / \mathrm{kg})$. All the recovery values were determined from analyses of the 72 pesticides in the matrices. The values were calculated using matrix-matched calibration standards, as stated in Section 3.3.1. Table 3 shows detailed recovery and repeatability data for all the pesticides analyzed in wine matrices. The recovery rates of all the pesticides were in the range of $70.2-108.8 \%$ (between 70.2 and $108.8 \%$ for white wine, and between 72.3 and $106.0 \%$ for red wine). The relative standard deviations (RSDs) were below $8.3 \%$ for all the cases. All the recovery values and RSDs are in the acceptable range of SANTE/12682/2019 [65]. 
Table 3. Average recovery, RSD, LOD and LOQ after application of the m-PFC procedure, determined by GC-MS/MS in wine.

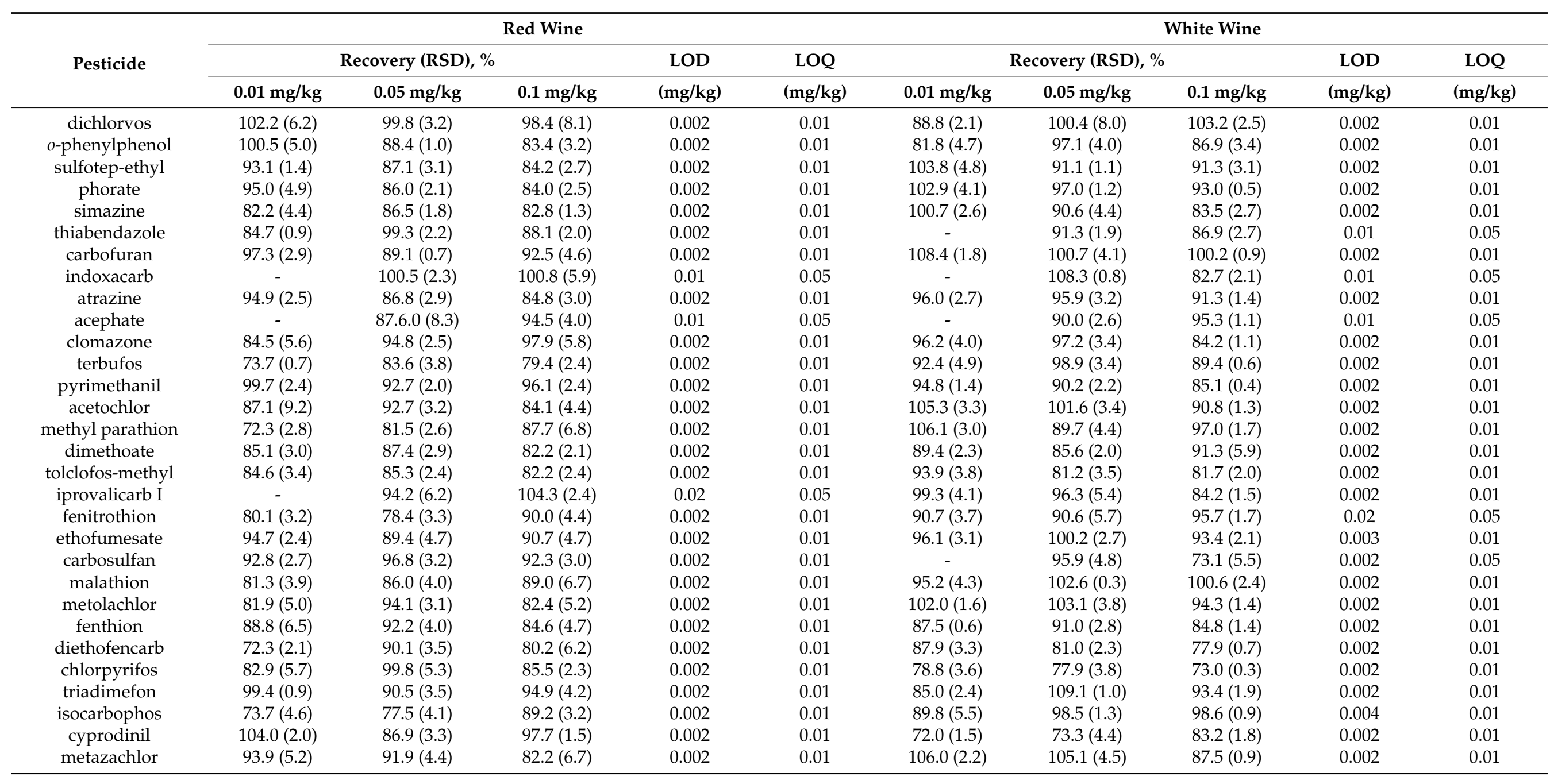


Table 3. Cont.

\begin{tabular}{|c|c|c|c|c|c|c|c|c|c|c|}
\hline \multirow{3}{*}{ Pesticide } & \multicolumn{5}{|c|}{ Red Wine } & \multicolumn{5}{|c|}{ White Wine } \\
\hline & \multicolumn{3}{|c|}{ Recovery (RSD), \% } & \multirow{2}{*}{$\frac{\text { LOD }}{\text { (mg/kg) }}$} & \multirow{2}{*}{$\frac{\text { LOQ }}{(\mathrm{mg} / \mathrm{kg})}$} & \multicolumn{3}{|c|}{ Recovery (RSD), \% } & \multirow{2}{*}{$\begin{array}{c}\text { LOD } \\
(\mathrm{mg} / \mathrm{kg})\end{array}$} & \multirow{2}{*}{$\frac{\text { LOQ }}{(\mathrm{mg} / \mathrm{kg})}$} \\
\hline & $0.01 \mathrm{mg} / \mathrm{kg}$ & $0.05 \mathrm{mg} / \mathrm{kg}$ & $0.1 \mathrm{mg} / \mathrm{kg}$ & & & $0.01 \mathrm{mg} / \mathrm{kg}$ & $0.05 \mathrm{mg} / \mathrm{kg}$ & $0.1 \mathrm{mg} / \mathrm{kg}$ & & \\
\hline pendimethalin & $84.1(1.9)$ & $80.8(4.6)$ & $72.8(3.9)$ & 0.002 & 0.01 & $86.8(8.3)$ & $78.6(3.6)$ & $74.7(1.1)$ & 0.002 & 0.01 \\
\hline chlorfenvinphos & $103.1(2.0)$ & $81.8(1.2)$ & $100.0(2.6)$ & 0.002 & 0.01 & $104.2(3.5)$ & $100.0(6.5)$ & $108.8(1.4)$ & 0.002 & 0.01 \\
\hline fipronil & $95.6(5.2)$ & $94.6(7.3)$ & $87.1(5.2)$ & 0.002 & 0.01 & $98.7(8.2)$ & $87.3(4.4)$ & $97.4(0.1)$ & 0.002 & 0.01 \\
\hline procymidone & $105.1(2.1)$ & $98.7(2.3)$ & $86.8(3.2)$ & 0.002 & 0.01 & $92.2(2.0)$ & $94.1(4.2)$ & $85.1(2.1)$ & 0.002 & 0.01 \\
\hline vinclozolin & $96.2(1.4)$ & $79.5(3.7)$ & $82.7(3.4)$ & 0.002 & 0.01 & $85.0(2.8)$ & $99.9(3.5)$ & $90.3(1.2)$ & 0.002 & 0.01 \\
\hline butachlor & $89.3(6.7)$ & $90.8(1.9)$ & $84.2(4.7)$ & 0.002 & 0.01 & $101.2(2.4)$ & $99.0(3.7)$ & $92.7(0.7)$ & 0.002 & 0.01 \\
\hline flutriafol & $93.8(0.9)$ & $85.2(0.5)$ & $84.2(2.3)$ & 0.002 & 0.01 & $94.0(2.3)$ & $92.4(2.1)$ & $94.5(2.5)$ & 0.002 & 0.01 \\
\hline carbaryl & - & $80.7(4.0)$ & $97.4(4.0)$ & 0.03 & 0.05 & $86.6(2.4)$ & $85.9(3.9)$ & $70.2(1.3)$ & 0.005 & 0.01 \\
\hline napropamide & $92.5(2.0)$ & $89.9(1.9)$ & $96.0(0.9)$ & 0.002 & 0.01 & $84.3(2.1)$ & $98.0(0.8)$ & $93.6(0.6)$ & 0.002 & 0.01 \\
\hline hexaconazole & $95.4(0.6)$ & $96.0(2.8)$ & $97.3(1.7)$ & 0.002 & 0.01 & $90.1(0.9)$ & $90.2(1.4)$ & $82.7(1.0)$ & 0.002 & 0.01 \\
\hline profenofos & $94.1(2.5)$ & $83.9(3.0)$ & $100.7(5.6)$ & 0.002 & 0.01 & $100.8(3.9)$ & $91.7(1.8)$ & $100.8(2.5)$ & 0.002 & 0.01 \\
\hline oxadiazon & $97.2(3.5)$ & $92.6(1.8)$ & $84.1(5.3)$ & 0.002 & 0.01 & $96.3(1.6)$ & $97.3(3.6)$ & $87.4(1.0)$ & 0.002 & 0.01 \\
\hline iprovalicarb II & - & $96.2(4.3)$ & $98.0(4.1)$ & 0.01 & 0.05 & - & $96.4(1.9)$ & $91.0(2.5)$ & 0.02 & 0.05 \\
\hline carboxin & $106.1(2.7)$ & $90.6(4.9)$ & $89.5(1.2)$ & 0.002 & 0.01 & $85.8(3.5)$ & $89.7(3.8)$ & $93.7(0.9)$ & 0.002 & 0.01 \\
\hline kresoxim-methyl & $83.6(2.9)$ & $84.9(0.8)$ & $81.4(4.2)$ & 0.002 & 0.01 & $101.0(1.4)$ & $95.5(2.3)$ & $88.4(1.7)$ & 0.002 & 0.01 \\
\hline metalaxyl & $79.8(2.3)$ & $78.0(2.2)$ & $84.8(4.3)$ & 0.002 & 0.01 & $92.0(6.3)$ & $90.5(3.4)$ & $88.8(0.8)$ & 0.002 & 0.01 \\
\hline diniconazole & $105.4(2.4)$ & $106.0(0.8)$ & $99.0(5.5)$ & 0.002 & 0.01 & $96.4(1.8)$ & $94.7(2.8)$ & $92.7(1.7)$ & 0.002 & 0.01 \\
\hline triazophos & - & $86.0(1.8)$ & $95.5(3.2)$ & 0.01 & 0.05 & $100.8(5.6)$ & $93.8(2.4)$ & $94.5(2.4)$ & 0.002 & 0.01 \\
\hline propiconazole I & $95.0(5.1)$ & $89.8(0.5)$ & $99.4(4.5)$ & 0.002 & 0.01 & $97.0(2.1)$ & $90.0(1.1)$ & $94.2(2.7)$ & 0.002 & 0.01 \\
\hline propiconazole II & $96.5(2.5)$ & $92.1(1.3)$ & $97.1(0.2)$ & 0.002 & 0.01 & $91.7(4.0)$ & $89.6(2.1)$ & $94.9(3.0)$ & 0.002 & 0.01 \\
\hline propyzamide & $92.8(3.4)$ & $85.6(2.3)$ & $101.9(2.6)$ & 0.002 & 0.01 & $98.3(2.1)$ & $91.3(2.2)$ & $94.2(2.9)$ & 0.002 & 0.01 \\
\hline diclofop-methyl & $99.2(2.3)$ & $89.6(3.1)$ & $96.1(4.5)$ & 0.002 & 0.01 & $93.3(4.6)$ & $92.6(5.3)$ & $81.2(1.3)$ & 0.002 & 0.01 \\
\hline epoxiconazole & - & $72.4(3.7)$ & $76.9(2.8)$ & 0.02 & 0.05 & - & $75.7(6.0)$ & $77.1(0.4)$ & 0.02 & 0.05 \\
\hline iprodione & $83.4(4.2)$ & $93.8(2.1)$ & $103.8(7.5)$ & 0.002 & 0.01 & $104.1(1.9)$ & $77.8(3.5)$ & $79.9(2.2)$ & 0.002 & 0.01 \\
\hline cypermethrin-I & $87.1(0.8)$ & $89.6(2.3)$ & $78.6(4.0)$ & 0.002 & 0.01 & $94.7(5.0)$ & $102.5(3.4)$ & $93.3(0.8)$ & 0.002 & 0.01 \\
\hline bifenthrin & $85.0(3.1)$ & $89.9(4.5)$ & $85.7(1.6)$ & 0.002 & 0.01 & $98.9(3.4)$ & $85.6(2.3)$ & $84.9(1.0)$ & 0.002 & 0.01 \\
\hline bifenox & $102.6(2.3)$ & $90.7(6.8)$ & $87.9(4.5)$ & 0.002 & 0.01 & $97.7(1.6)$ & $104.3(1.2)$ & $103.4(3.8)$ & 0.002 & 0.01 \\
\hline
\end{tabular}


Table 3. Cont.

\begin{tabular}{|c|c|c|c|c|c|c|c|c|c|c|}
\hline \multirow{3}{*}{ Pesticide } & \multicolumn{5}{|c|}{ Red Wine } & \multicolumn{5}{|c|}{ White Wine } \\
\hline & \multicolumn{3}{|c|}{ Recovery (RSD), \% } & \multirow{2}{*}{$\begin{array}{c}\text { LOD } \\
(\mathrm{mg} / \mathrm{kg})\end{array}$} & \multirow{2}{*}{$\begin{array}{c}\text { LOQ } \\
(\mathrm{mg} / \mathrm{kg})\end{array}$} & \multicolumn{3}{|c|}{ Recovery (RSD), \% } & \multirow{2}{*}{$\frac{\text { LOD }}{(\mathrm{mg} / \mathrm{kg})}$} & \multirow{2}{*}{$\frac{\text { LOQ }}{(\mathrm{mg} / \mathrm{kg}}$} \\
\hline & $0.01 \mathrm{mg} / \mathrm{kg}$ & $0.05 \mathrm{mg} / \mathrm{kg}$ & $0.1 \mathrm{mg} / \mathrm{kg}$ & & & $0.01 \mathrm{mg} / \mathrm{kg}$ & $0.05 \mathrm{mg} / \mathrm{kg}$ & $0.1 \mathrm{mg} / \mathrm{kg}$ & & \\
\hline cypermethrin II & - & $91.7(2.9)$ & $93.4(1.6)$ & 0.01 & 0.05 & $91.0(2.8)$ & $100.6(2.0)$ & $83.7(0.8)$ & 0.002 & 0.01 \\
\hline beta-cypermethrin & - & $91.7(2.9)$ & $93.4(1.6)$ & 0.01 & 0.05 & $91.0(2.8)$ & $100.6(2.0)$ & $83.7(0.8)$ & 0.002 & 0.01 \\
\hline cypermethrin III & - & $103.6(4.5)$ & $94.2(3.9)$ & 0.01 & 0.05 & $98.5(5.5)$ & $105.8(2.5)$ & $105.4(1.9)$ & 0.002 & 0.01 \\
\hline permethrin I & - & $94.7(2.3)$ & $97.2(3.2)$ & 0.01 & 0.05 & - & $104.2(0.8)$ & $104.9(2.5)$ & 0.02 & 0.05 \\
\hline permethrin II & $83.7(1.7)$ & $83.9(2.1)$ & $98.1(4.6)$ & 0.003 & 0.01 & $95.7(2.0)$ & $93.2(1.5)$ & $96.0(2.7)$ & 0.002 & 0.01 \\
\hline cypermethrin IV & - & $94.7(3.0)$ & $95.7(2.3)$ & 0.01 & 0.05 & - & $101.7(1.1)$ & $92.9(1.9)$ & 0.01 & 0.05 \\
\hline difenoconazole & $94.2(4.3)$ & $93.7(2.6)$ & $95.1(3.5)$ & 0.002 & 0.01 & $94.6(2.8)$ & $89.9(1.0)$ & $93.1(2.2)$ & 0.002 & 0.01 \\
\hline azoxystrobin & - & $98.2(6.1)$ & $95.2(1.7)$ & 0.01 & 0.05 & - & 91.2.0 (4.1) & $103.6(1.3)$ & 0.01 & 0.05 \\
\hline deltamethrin I & - & $95.8(3.3)$ & $91.6(4.6)$ & 0.01 & 0.05 & $96.4(3.2)$ & $101.3(0.7)$ & $98.8(1.8)$ & 0.002 & 0.01 \\
\hline deltamethrin II & - & $96.1(2.7)$ & $95.2(3.5)$ & 0.01 & 0.05 & $98.3(1.1)$ & $97.9(3.6)$ & $84.8(2.1)$ & 0.002 & 0.01 \\
\hline
\end{tabular}




\subsubsection{Limits of Quantitation and Limits of Detection}

The described method was tested for the simultaneous extraction and determination of 72 analytes in wine matrices, which manifested varying LODs and LOQs. Since LODs and LOQs are matrix-dependent, it is recommended to perform matrix-matched calibrations for the quantitative analysis of unknown samples in complex matrices. Table 3 shows the LOD and LOQ values for the pesticides in wine under study. The LODs and LOQs ranged from 0.002 to $0.01 \mathrm{mg} / \mathrm{kg}$ and from 0.01 to $0.05 \mathrm{mg} / \mathrm{kg}$, respectively.

In general, the validation data for all the analytes were in accordance with the EU guidelines (2019) SANTE/12682/2019 [65] for pesticide residue analysis, reflecting the good performance of the method. Comparison with other QuEChERS methods for determining pesticides in grape wines, the m-PFC method which our group has proposed, showed significant advantages in terms of the amount of time that is consumed, each sample took less than two minutes for m-PFC cleanup, so it would be time-saving during the processing of enormous samples. Regarding recoveries, RSDs, LOQs and the number of pesticides, the m-PFC method presented similar effects when compared to other methods (Table 4).

Table 4. Comparison of the proposed method with other QuEChERS methods.

\begin{tabular}{|c|c|c|c|c|c|c|}
\hline Method & Detecting Instrument & $\begin{array}{c}\text { Recoveries } \\
(\%)\end{array}$ & $\begin{array}{l}\text { RSD } \\
(\%)\end{array}$ & $\begin{array}{l}\mathrm{LOQ} \\
(\mu \mathrm{g} / \mathrm{kg})\end{array}$ & $\begin{array}{l}\text { Number of } \\
\text { Pesticides }\end{array}$ & $\begin{array}{l}\text { Cleanup Time Cost } \\
\text { per Sample (Min) }\end{array}$ \\
\hline m-PFC Method & GC-MS/MS & $70.2-108.8$ & $\leq 9.2$ & $10-50$ & 72 & $\leq 2$ \\
\hline Payá et al. [45] & $\begin{array}{l}\text { GC-MS/MS, } \\
\text { LC-MS/MS }\end{array}$ & $60-127$ & $1.2-16.7$ & 10 & 42 & $\geq 10$ \\
\hline $\begin{array}{l}\text { Romero-González } \\
\text { et al. [46] }\end{array}$ & UHPLC-MS/MS & $70-120$ & $\leq 24$ & 10 & 90 & $\geq 10$ \\
\hline Martínez et al. [47] & LC/MS/MS & $73-87$ & $2-16$ & 10 & 9 & $\geq 10$ \\
\hline $\begin{array}{c}\text { Santana-Mayor } \\
\text { et al. [17] }\end{array}$ & $\begin{array}{c}\text { UHPLC-(Q-ToF)- } \\
\text { MS/MS or } \\
\text { GC-QqQ-MS/MS }\end{array}$ & $75-100$ & $5-20$ & $2.6-21.39$ & 173 & $\geq 10$ \\
\hline Bernardi et al. [48] & UHPLC-(HR)MS/MS & 70-120 & $\leq 20$ & 10 & 90 & $\geq 10$ \\
\hline Kosma et al. [49] & UHPLC-Orbitrap-MS & $71.2-125$ & $\leq 11$ & $2.5-73$ & & $\geq 10$ \\
\hline $\begin{array}{c}\text { Schusterova } \\
\text { et al. [7] }\end{array}$ & UHPLC-(HR)MS/MS & $70-120$ & $1-20$ & 1 & 367 & $\geq 10$ \\
\hline
\end{tabular}

\subsection{Method Application}

The developed QuEChERS method with a m-PFC cleanup step was applied to real samples. Seventy reference samples (50 for red wine samples and 20 for white wine samples) from the supermarkets in Beijing were treated and analyzed by GC-MS/MS. Since MRLs have not yet been set for wine, according to SANTE/2020/12830 [66] and EC 657/2002 [67], it is accepted that the MRLs for wine are the same as those for wine grapes. Table 5 shows the detected concentrations of pesticides in the real samples from supermarkets in Beijing. Pesticide residues were detected in seven samples (10\%). The most frequently detected pesticides were difenoconazole $(2.9 \%)$, pyridaben $(4.3 \%)$, carbosulfan $(2.9 \%)$, pyr imethanil $(1.4 \%)$, propyzamide $(1.4 \%)$, simazine $(4.3 \%)$ and atrazine $(4.3 \%)$. To date, and with regard to grapevine products, MRLs have only been set for grapes, taking the transfer in the wine into account. The MRLs for wine are still not widely established [15-17]. Therefore, we referred to the maximum permitted residue levels set by EU2018/555 [68], The concentrations of pesticides in the selected wine samples did not exceed the permitted residue levels. 
Table 5. The detected concentrations of pesticides in the real samples from supermarkets in Beijing.

\begin{tabular}{|c|c|c|c|c|c|c|c|}
\hline \multirow{2}{*}{ Pesticide } & \multicolumn{7}{|c|}{$\mathrm{X} \pm \mathrm{SD}^{\mathrm{a}, \mathrm{n}}$} \\
\hline & Red Wine-03 & Red Wine-04 & Red Wine-15 & Red Wine-22 & Red Wine-27 & Red Wine-46 & White Wine-03 \\
\hline difenoconazole & ND & $0.010 \pm 0.001$ & ND & ND & $0.016 \pm 0.003$ & ND & ND \\
\hline pyridaben & ND & ND & $0.012 \pm 0.003$ & $0.019 \pm 0.004$ & ND & $0.012 \pm 0.003$ & ND \\
\hline carbosulfan & ND & ND & ND & ND & ND & $0.026 \pm 0.005$ & $0.054 \pm 0.011$ \\
\hline pyrimethanil & ND & ND & $0.031 \pm 0.006$ & ND & ND & ND & ND \\
\hline propyzamide & ND & ND & $0.035 \pm 0.007$ & ND & ND & ND & ND \\
\hline simazine & $0.014 \pm 0.003$ & $0.013 \pm 0.002$ & $0.042 \pm 0.009$ & ND & ND & ND & ND \\
\hline atrazine & $0.015 \pm 0.004$ & $0.016 \pm 0.003$ & $0.012 \pm 0.002$ & ND & ND & ND & ND \\
\hline
\end{tabular}

${ }^{a}$ The average concentration $(\mathrm{X})$ and standard deviation (SD) of each compound were calculated considering the pesticide residues below the limit of quantification (LOQ) for the method as non-detected(ND); ${ }^{n}$ the number of 3 times each sample had been analyzed.

\section{Conclusions}

An efficient and effective m-PFC multi-residue method was developed for the determination of 72 pesticides in wine by GC-MS/MS. The m-PFC method, which could be carried out without any solvent evaporation, vortexing or centrifugation procedure, proved to be a simple and rapid cleanup method. The method achieved high-quality results (good repeatability and recovery, and a wide analytical scope) and had several practical benefits (low cost, little labor, high sample throughput, hardly any waste and low labware equipment and space demands). The method was found to be very sensitive and gave a LOQ of $<0.05 \mathrm{mg} / \mathrm{kg}$ for all the analytes. In conclusion, m-PFC could be used as a feasible, convenient and rapid high-throughput cleanup method for the analysis of analytes in wine.

Author Contributions: Conceptualization, S.L. and C.P.; methodology, A.B. and L.Z.; software, C.L.; validation, Y.H., C.Y. and L.S.; formal analysis, S.L.; investigation, C.Y.; resources, A.B.; data curation, L.S.; Writing-Original draft preparation, N.Z.; Writing-Review and editing, C.P.; visualization, L.S.; supervision, C.L.; project administration, S.L.; funding acquisition, C.P. All authors have read and agreed to the published version of the manuscript.

Funding: Guangxi Key Research and Development Program (No. AB21196039); Hunan Agricultural Science and Technology Innovation Fund Project (No. 2018QN35); The Program of The Central Government Providing Special Funds for Guiding Local Governments in Science and Technology Development (No. 2019XF5076).

Conflicts of Interest: The authors declare no conflict of interest.

\section{References}

1. Holahan, C.J.; Schutte, K.K.; Brennan, P.L.L.; North, R.J.; Holahan, C.K.; Moos, B.S.; Moos, R.H. Wine consumption and 20-year mortality among late-life moderate drinkers. J. Stud. Alcohol Drugs 2012, 73, 80-88. [CrossRef] [PubMed]

2. Covas, M.I.; Gambert, P.; Fitó, M.; de la Torre, R. Wine and oxidative stress: Up-to-date evidence of the effects of moderate wine consumption on oxidative damage in humans. Atherosclerosis 2010, 208, 297-304. [CrossRef] [PubMed]

3. The International Organisation of Vine and Wine. Available online: http://www.oiv.int/oiv/info/enpublicationsstatistiques (accessed on 28 September 2021).

4. Moeder, M.; Bauer, C.; Popp, P.; Van Pinxteren, M.; Reemtsma, T. Determination of pesticide residues in wine by membraneassisted solvent extraction and high-performance liquid chromatography-tandem mass spectrometry. Anal. Bioanal. Chem. 2012, 403, 1731-1741. [CrossRef] [PubMed]

5. Yigit, N.; Velioglu, Y.S. Effects of processing and storage on pesticide residues in foods. Crit. Rev. Food Sci. Nutr. 2019, 60, 1-20. [CrossRef]

6. Rahman, S.; Mele, M.A.; Lee, Y.-T.; Islam, M.Z. Consumer preference, quality, and safety of organic and conventional fresh fruits, vegetables, and cereals. Foods 2021, 10, 105. [CrossRef]

7. Schusterova, D.; Hajslova, J.; Kocourek, V.; Pulkrabova, J. Pesticide residues and their metabolites in grapes and wines from conventional and organic farming system. Foods 2021, 10, 307. [CrossRef]

8. Yang, M.; Luo, F.; Zhang, X.; Zhou, L.; Lou, Z.; Zhao, M.; Chen, Z. Dissipation and risk assessment of multiresidual fungicides in grapes under field conditions. J. Agric. Food Chem. 2020, 68, 1071-1078. [CrossRef]

9. Jin, B.; Xie, L.; Guo, Y.; Pang, G. Multi-residue detection of pesticides in juice and fruit wine: A review of extraction and detection methods. Food Res. Int. 2012, 46, 399-409. [CrossRef] 
10. Tsakiris, I.; Tzatzarakis, M.; Alegakis, A.; Mitlianga, P.; Kavvalakis, M.; Vakonaki, E.; Goumenou, M.; Stivaktakis, P.; Tsatsakis, A. Monitoring of pesticides residues in Greek bottled wine. Toxicol. Lett. 2014, 229, S184. [CrossRef]

11. Čuš, F.; Česnik, H.B.; Bolta, Š.V.; Gregorčič, A. Pesticide residues and microbiological quality of bottled wines. Food Control 2010, 21, 150-154. [CrossRef]

12. Angioni, A.; Dedola, F. Three years monitoring survey of pesticide residues in Sardinia wines following integrated pest management strategies. Environ. Monit. Assess. 2013, 185, 4281-4289. [CrossRef]

13. He, Z.; Xu, Y.; Wang, L.; Peng, Y.; Luo, M.; Cheng, H.; Liu, X. Wide-scope screening and quantification of 50 pesticides in wine by liquid chromatography/quadrupole time-of-flight mass spectrometry combined with liquid chromatography/quadrupole linear ion trap mass spectrometry. Food Chem. 2016, 196, 1248-1255. [CrossRef]

14. Oliva, J.; Martínez-Gil, A.; Lorenzo, C.; Cámara, M.; Salinas, M.; Barba, A.; Garde-Cerdán, T. Influence of the use of fungicides on the volatile composition of Monastrell red wines obtained from inoculated fermentation. Food Chem. 2015, 170, 401-406. [CrossRef]

15. Celeiro, M.; Llompart, M.; Lamas, J.P.; Lores, M.; Garcia-Jares, C.; Dagnac, T. Determination of fungicides in white grape bagasse by pressurized liquid extraction and gas chromatography tandem mass spectrometry. J. Chromatogr. A 2014, 1343, 18-25. [CrossRef]

16. Pelajić, M.; Peček, G.; Pavlović, D.M.; Čepo, D.V. Novel multiresidue method for determination of pesticides in red wine using gas chromatography-mass spectrometry and solid phase extraction. Food Chem. 2016, 200, 98-106. [CrossRef]

17. Santana-Mayor, Á.; Rodríguez-Ramos, R.; Socas-Rodríguez, B.; Díaz-Romero, C.; Rodríguez-Delgado, M. Comparison of pesticide residue levels in red wines from Canary Islands, Iberian Peninsula, and Cape Verde. Foods 2020, 9, 1555. [CrossRef]

18. González-Rodríguez, R.M.; Cancho-Grande, B.; Simal-Gándara, J. Multiresidue determination of 11 new fungicides in grapes and wines by liquid-liquid extraction/clean-up and programmable temperature vaporization injection with analyte protectants/gas chromatography/ion trap mass spectrometry. J. Chromatogr. A 2009, 1216, 6033-6042. [CrossRef]

19. Zhong, X.-D.; Fu, D.-S.; Wu, P.-P.; Liu, Q.; Lin, G.-C.; Cao, S.-H.; Li, Y.-Q. Rapid fluorescence spectroscopic screening method for the sensitive detection of thiabendazole in red wine. Anal. Methods 2014, 6, 7260-7267. [CrossRef]

20. Uclés, A.; García, A.V.; Gil García, M.D.; del Real, A.M.A.; Fernández-Alba, A.R. Benzimidazole and imidazole fungicide analysis in grape and wine samples using a competitive enzyme-linked immunosorbent assay. Anal. Methods 2015, 7, 9158-9165. [CrossRef]

21. Economou, A.; Botitsi, H.; Antoniou, S.; Tsipi, D. Determination of multi-class pesticides in wines by solid-phase extraction and liquid chromatography-tandem mass spectrometry. J. Chromatogr. A 2009, 1216, 5856-5867. [CrossRef]

22. Carpinteiro, I.; Ramil, M.; Rodríguez, I.; Cela, R. Determination of fungicides in wine by mixed-mode solid phase extraction and liquid chromatography coupled to tandem mass spectrometry. J. Chromatogr. A 2010, 1217, 7484-7492. [CrossRef]

23. Pang, G.-F.; Fan, C.-L.; Liu, Y.-M.; Cao, Y.-Z.; Zhang, J.-J.; Fu, B.-L.; Li, X.-M.; Li, Z.-Y.; Wu, Y.-P. Multi-residue method for the determination of 450 pesticide residues in honey, fruit juice and wine by double-cartridge solid-phase extraction/gas chromatography-mass spectrometry and liquid chromatography-tandem mass spectrometry. Food Addit. Contam. 2006, 23, 777-810. [CrossRef]

24. Walorczyk, S.; Drozdzynski, D.; Gnusowski, B. Multiresidue determination of 160 pesticides in wines employing mixed-mode dispersive-solid phase extraction and gas chromatography-tandem mass spectrometry. Talanta 2011, 85, 1856-1870. [CrossRef]

25. Fontana, A.; Rodríguez, I.; Ramil, M.; Altamirano, J.; Cela, R. Solid-phase extraction followed by liquid chromatography quadrupole time-of-flight tandem mass spectrometry for the selective determination of fungicides in wine samples. J. Chromatogr. A 2011, 1218, 2165-2175. [CrossRef]

26. Pérez-Ortega, P.; Gilbert-López, B.; García-Reyes, J.F.; Ramos-Martos, N.; Molina-Díaz, A. Generic sample treatment method for simultaneous determination of multiclass pesticides and mycotoxins in wines by liquid chromatography-mass spectrometry. $J$. Chromatogr. A 2012, 1249, 32-40. [CrossRef]

27. Beneito-Cambra, M.; Pérez-Ortega, P.; Molina-Díaz, A.; García-Reyes, J.F. Rapid determination of multiclass fungicides in wine by low-temperature plasma (LTP) ambient ionization mass spectrometry. Anal. Methods 2015, 7, 7345-7351. [CrossRef]

28. Zambonin, C.G.; Quinto, M.; De Vietro, N.; Palmisano, F. Solid-phase microextraction—Gas chromatography mass spectrometry: A fast and simple screening method for the assessment of organophosphorus pesticides residues in wine and fruit juices. Food Chem. 2004, 86, 269-274. [CrossRef]

29. Fontana, A.; Rodríguez, I.; Ramil, M.; Altamirano, J.; Cela, R. Liquid chromatography time-of-flight mass spectrometry following sorptive microextraction for the determination of fungicide residues in wine. Anal. Bioanal. Chem. 2011, 401, 767-775. [CrossRef]

30. You, X.; Wang, S.; Liu, F.; Shi, K. Ultrasound-assisted surfactant-enhanced emulsification microextraction based on the solidification of a floating organic droplet used for the simultaneous determination of six fungicide residues in juices and red wine. $J$. Chromatogr. A 2013, 1300, 64-69. [CrossRef]

31. Viñas, P.; Martínez-Castillo, N.; Campillo, N.; Hernández-Córdoba, M. Liquid-liquid microextraction methods based on ultrasound-assisted emulsification and single-drop coupled to gas chromatography-mass spectrometry for determining strobilurin and oxazole fungicides in juices and fruits. J. Chromatogr. A 2010, 1217, 6569-6577. [CrossRef]

32. Garbi, A.; Sakkas, V.; Fiamegos, Y.C.; Stalikas, C.D.; Albanis, T. Sensitive determination of pesticides residues in wine samples with the aid of single-drop microextraction and response surface methodology. Talanta 2010, 82, 1286-1291. [CrossRef] [PubMed] 
33. Cabo, T.R.; Rodríguez, I.; Ramil, M.; Cela, R. Dispersive liquid-liquid microextraction using non-chlorinated, lighter than water solvents for gas chromatography-Mass spectrometry determination of fungicides in wine. J. Chromatogr. A 2011, 1218, 6603-6611. [CrossRef] [PubMed]

34. Dos Anjos, J.P.; de Andrade, J.B. Simultaneous determination of pesticide multiresidues in white wine and rosé wine by SDME/GC-MS. Microchem. J. 2015, 120, 69-76. [CrossRef]

35. Montes, R.; Rodríguez, I.; Ramil, M.; Rubí, E.; Cela, R. Solid-phase extraction followed by dispersive liquid-liquid microextraction for the sensitive determination of selected fungicides in wine. J. Chromatogr. A 2009, 1216, 5459-5466. [CrossRef]

36. Cabo, T.R.; Rodríguez, I.; Cela, R. Determination of hydroxylated stilbenes in wine by dispersive liquid-liquid microextraction followed by gas chromatography mass spectrometry. J. Chromatogr. A 2012, 1258, 21-29. [CrossRef]

37. Gure, A.; Lara, F.J.; García-Campaña, A.M.; Megersa, N.; del Olmo-Iruela, M. Vortex-assisted ionic liquid dispersive liquidliquid microextraction for the determination of sulfonylurea herbicides in wine samples by capillary high-performance liquid chromatography. Food Chem. 2015, 170, 348-353. [CrossRef]

38. Anastassiades, M.; Lehotay, S.J.; Štajnbaher, D.; Schenck, F.J. Fast and easy multiresidue method employing acetonitrile extraction/partitioning and "Dispersive Solid-Phase Extraction" for the determination of pesticide residues in produce. J. AOAC Int. 2003, 86, 412-431. [CrossRef]

39. Lehotay, S.J.; Son, K.A.; Kwon, H.; Koesukwiwat, U.; Fu, W.; Mastovska, K.; Hoh, E.; Leepipatpiboon, N. Comparison of QuEChERS sample preparation methods for the analysis of pesticide residues in fruits and vegetables. J. Chromatogr. A 2010, 1217, 2548-2560. [CrossRef]

40. Zhang, K.; Wong, J.W.; Hayward, D.G.; Sheladia, P.; Krynitsky, A.J.; Schenck, F.J.; Webster, M.G.; Ammann, J.A.; Ebeler, S. Multiresidue pesticide analysis of wines by dispersive solid-phase extraction and ultrahigh-performance liquid chromatography-tandem mass spectrometry. J. Agric. Food Chem. 2009, 57, 4019-4029. [CrossRef]

41. Jiang, Y.; Li, X.; Xu, J.; Pan, C.; Zhang, J.; Niu, W. Multiresidue method for the determination of 77 pesticides in wine using QuEChERS sample preparation and gas chromatography with mass spectrometry. Food Addit. Contam. Part. A 2009, 26, 859-866. [CrossRef]

42. Cunha, S.; Fernandes, J.; Alves, A.; Oliveira, B. Fast low-pressure gas chromatography-mass spectrometry method for the determination of multiple pesticides in grapes, musts and wines. J. Chromatogr. A 2009, 1216, 119-126. [CrossRef]

43. Patil, S.H.; Banerjee, K.; Dasgupta, S.; Oulkar, D.P.; Patil, S.B.; Jadhav, M.R.; Savant, R.H.; Adsule, P.G.; Deshmukh, M.B. Multiresidue analysis of 83 pesticides and 12 dioxin-like polychlorinated biphenyls in wine by gas chromatography-time-of-flight mass spectrometry. J. Chromatogr. A 2009, 1216, 2307-2319. [CrossRef]

44. Stadler, R.H.; Tran, L.-A.; Cavin, C.; Zbinden, P.; Konings, E.J.M. Analytical approaches to verify food integrity: Needs and challenges. J. AOAC Int. 2016, 99, 1135-1144. [CrossRef]

45. Payá, P.; Anastassiades, M.; Mack, D.; Sigalova, I.; Tasdelen, B.; Oliva, J.; Barba, A. Analysis of pesticide residues using the Quick Easy Cheap Effective Rugged and Safe (QuEChERS) pesticide multiresidue method in combination with gas and liquid chromatography and tandem mass spectrometric detection. Anal. Bioanal. Chem. 2007, 389, 1697-1714. [CrossRef]

46. Romero-González, R.; Frenich, A.G.; Vidal, J.M.; Prestes, O.D.; Grio, S. Simultaneous determination of pesticides, biopesticides and mycotoxins in organic products applying a quick, easy, cheap, effective, rugged and safe extraction procedure and ultra-high performance liquid chromatography-tandem mass spectrometry. J. Chromatogr. A 2011, 1218, 1477-1485. [CrossRef]

47. Martínez, G.; Morales, A.; Maestro, A.; Cermeño, S.; Oliva, J.; Barba, A. Determination of nine fungicides in grape and wine using QuEChERS Extraction and LC/MS/MS analysis. J. AOAC Int. 2015, 98, 1745-1751. [CrossRef]

48. Bernardi, G.; Kemmerich, M.; Adaime, M.B.; Prestes, O.D.; Zanella, R. Miniaturized QuEChERS method for determination of 97 pesticide residues in wine by ultra-high performance liquid chromatography coupled with tandem mass spectrometry. Anal. Methods 2020, 12, 2682-2692. [CrossRef]

49. Kosma, C.I.; Koloka, O.L.; Albanis, T.A.; Konstantinou, I.K. Accurate mass screening of pesticide residues in wine by modified QuEChERS and LC-hybrid LTQ/Orbitrap-MS. Food Chem. 2021, 360, 130008. [CrossRef]

50. Iijima, S. Helical microtubules of graphitic carbon. Nature 1991, 354, 56-58. [CrossRef]

51. Petrovic, M.; Farre, M.; de Alda, M.L.; Pérez, S.; Postigo, C.; Köck-Schulmeyer, M.; Radjenovic, J.; Gros, M.; Barceló, D. Recent trends in the liquid chromatography-mass spectrometry analysis of organic contaminants in environmental samples. J. Chromatogr. A 2010, 1217, 4004-4017. [CrossRef]

52. Ren, J.; Li, L.; Chen, C.; Chen, X.; Cai, Z.; Qiu, L.; Wang, Y.; Zhu, X.; Peng, H. Twisting carbon nanotube fibers for both wire-shaped micro-supercapacitor and micro-battery. Adv. Mater. 2013, 25, 1155-1159. [CrossRef]

53. Asensio-Ramos, M.; Hernández-Borges, J.; Borges-Miquel, T.; Rodríguez-Delgado, M. Evaluation of multi-walled carbon nanotubes as solid-phase extraction adsorbents of pesticides from agricultural, ornamental and forestal soils. Anal. Chim. Acta 2009, 647, 167-176. [CrossRef]

54. Valcárcel, M.; Cárdenas, A.S.; Simonet, B.M. Role of carbon nanotubes in analytical science. Anal. Chem. 2007, 79, 4788-4797. [CrossRef]

55. Morales-Cid, G.; Fekete, A.; Simonet, B.M.; Lehmann, R.; Cárdenas, S.; Zhang, X.; Valcárcel, M.; Schmitt-Kopplin, P. In situ synthesis of magnetic multiwalled carbon nanotube composites for the clean-up of (fluoro)quinolones from human plasma prior to ultrahigh pressure liquid chromatography analysis. Anal. Chem. 2010, 82, 2743-2752. [CrossRef] 
56. Zhao, P.; Wang, L.; Zhou, L.; Zhang, F.; Kang, S.; Pan, C. Multi-walled carbon nanotubes as alternative reversed-dispersive solid phase extraction materials in pesticide multi-residue analysis with QuEChERS method. J. Chromatogr. A 2012, 1225, 17-25. [CrossRef]

57. Zhao, P.; Wang, L.; Luo, J.; Li, J.; Pan, C. Determination of pesticide residues in complex matrices using multi-walled carbon nanotubes as reversed-dispersive solid-phase extraction sorbent. J. Sep. Sci. 2011, 35, 153-158. [CrossRef]

58. Zhao, P.; Wang, L.; Jiang, Y.; Zhang, F.; Pan, C. Dispersive cleanup of acetonitrile extracts of tea samples by mixed multiwalled carbon nanotubes, primary secondary amine, and graphitized carbon black sorbents. J. Agric. Food Chem. 2012, 60, 4026-4033. [CrossRef]

59. Meng, Z.; Li, Q.; Cong, J.; Huang, Y.; Wang, D.; Pan, C.; Fan, S.; Zhang, Y. Rapid screening of 350 pesticide residues in vegetable and fruit juices by multi-plug filtration cleanup method combined with gas chromatography-electrostatic field orbitrap high resolution mass spectrometry. Foods 2021, 10, 1651. [CrossRef]

60. Guan, W.; Li, Z.; Zhang, H.; Hong, H.; Rebeyev, N.; Ye, Y.; Ma, Y. Amine modified graphene as reversed-dispersive solid phase extraction materials combined with liquid chromatography-tandem mass spectrometry for pesticide multi-residue analysis in oil crops. J. Chromatogr. A 2013, 1286, 1-8. [CrossRef]

61. You, X.; Liang, L.; Liu, F. Dissipation and residues of clethodim and its oxidation metabolites in a rape-field ecosystem using QuEChERS and liquid chromatography/tandem mass spectrometry. Food Chem. 2014, 143, 170-174. [CrossRef]

62. Zhao, P.; Fan, S.; Yu, C.; Zhang, J.; Pan, C. Multiplug filtration clean-up with multiwalled carbon nanotubes in the analysis of pesticide residues using LC-ESI-MS/MS. J. Sep. Sci. 2013, 36, 3379-3386. [CrossRef] [PubMed]

63. Zhao, P.; Huang, B.; Li, Y.; Han, Y.; Zou, N.; Gu, K.; Li, X.; Pan, C. Rapid multiplug filtration cleanup with multiple-walled carbon nanotubes and gas chromatography-triple-quadruple mass spectrometry detection for 186 pesticide residues in tomato and tomato products. J. Agric. Food Chem. 2014, 62, 3710-3725. [CrossRef] [PubMed]

64. Qin, Y.; Zhao, P.; Fan, S.; Han, Y.; Li, Y.; Zou, N.; Song, S.; Zhang, Y.; Li, F.; Li, X.; et al. The comparison of dispersive solid phase extraction and multi-plug filtration cleanup method based on multi-walled carbon nanotubes for pesticides multi-residue analysis by liquid chromatography tandem mass spectrometry. J. Chromatogr. A 2015, 1385, 1-11. [CrossRef] [PubMed]

65. European Commission. Analytical Quality Control and Method Validation for Pesticide Residues Analysis in Food and Feed. 2019. Available online: https:/ / ec.europa.eu/food/system/files/2020-01/pesticides_mrl_guidelines_wrkdoc_2019-12682.pdf (accessed on 28 September 2021).

66. Guidance Document on Pesticide Analytical Methods for Risk Assessment and Post-Approval Control and Monitoring Purposes. 2021. Available online: https:/ / ec.europa.eu/food/system/files/2021-03/pesticides_ppp_app-proc_guide_res_mrl-guidelines2020-12830.pdf (accessed on 28 September 2021).

67. Commission Decision. (EC) No 657/2002 of 12 August 2002 implementing Council Directive 96/23/EC concerning the performance of analytical methods and the interpretation of results. Off. J. Eur. Communities 2002, L221, 8-36.

68. Commission Decision. European Commission Implementing Regulation (EU) 2018/555 of 9 April 2018 concerning a coordinated multiannual control programme of the Union for 2019, 2020 and 2021 to ensure compliance with maximum residue levels of pesticides and to assess the consumer exposure. Off. J. Eur. Communities 2018, 2016, 48-119. 